\title{
Process-Oriented Review of Bacterial Quorum Quenching for Membrane Biofouling Mitigation in Membrane Bioreactors (MBRs)
}

\author{
Naila Bouayed ${ }^{1, *}$, Nicolas Dietrich ${ }^{1}$, Christine Lafforgue ${ }^{1}$, Chung-Hak Lee ${ }^{2}$ \\ and Christelle Guigui ${ }^{1}$ \\ 1 LISBP—Laboratoire d'Ingénierie des Systèmes Biologiques et des Procédés), CNRS—Centre National de la \\ Recherche Scientifique), INRA—Institut National de la Recherche Agronomique), INSA—Institut National \\ des Sciences Appliquées), Université de Toulouse, Toulouse 31077, France; dietrich@insa-toulouse.fr (N.D.); \\ lafforgu@insa-toulouse.fr (C.L.); guigui@insa-toulouse.fr (C.G.) \\ 2 School of Chemical and Biological Engineering, Seoul National University, Seoul 08826, Korea; \\ leech@snu.ac.kr \\ * Correspondence: bouayed@insa-toulouse.fr; Tel.: +33-5-6155-9791
}

Academic Editor: Angelo Basile

Received: 27 October 2016; Accepted: 5 December 2016; Published: 13 December 2016

\begin{abstract}
Quorum Quenching (QQ) has been developed over the last few years to overcome practical issues related to membrane biofouling, which is currently the major difficulty thwarting the extensive development of membrane bioreactors (MBRs). QQ is the disruption of Quorum Sensing (QS), cell-to-cell communication enabling the bacteria to harmonize their behavior. The production of biofilm, which is recognized as a major part of the biocake formed on a membrane surface, and which leads to biofouling, has been found to be one of the bacterial behaviors controlled by QS. Since the enzymatic disruption of QS was reported to be efficient as a membrane biofouling mitigation technique in MBRs, the application of $Q Q$ to lab-scale MBRs has been the subject of much research using different approaches under different operating conditions. This paper gives an overview of the effectiveness of QQ in mitigating membrane biofouling in MBRs. It is based on the results of previous studies, using two microbial strains, Rhodococcus sp. BH4 and Pseudomonas sp. 1A1. The effect of bacterial QQ on the physical phenomena of the MBR process is analyzed, adopting an original multi-scale approach. Finally, the potential influence of the MBR operating conditions on QQ effectiveness is discussed.
\end{abstract}

Keywords: membrane bioreactors; biofouling; biofilm; Quorum Sensing; Quorum Quenching; acyl-homoserine lactones; acylase; lactonase; extracellular polymeric substances (EPS)

\section{Introduction}

Membrane bioreactors (MBRs) are considered as the most effective technology in advanced wastewater treatment (WWT). In comparison to other conventional WWT processes, MBRs provide excellent water quality with a smaller footprint, offering a great potential for water reuse. However, membrane fouling remains a major obstacle that still tends to hold back the wide application of MBRs. Membrane fouling is a term that encompasses all the phenomena inducing the deterioration of membrane performance by a severe loss of permeability, which further results in higher energy consumption to maintain the process productivity and a heightened need to clean or replace the membrane, which finally leads to a substantial increase in operating costs.

Membrane fouling is partly attributed to biofouling, which is defined as the complex combination of several mechanisms: deposition and accumulation of biosolids from the mixed liquor (microbial cells, microbial flocs), microbial growth on the membrane, pore clogging by microorganisms and 
adsorption of secreted microbial products, which results in the formation of a complex biocake on the membrane. A major part of the biocake is composed of biofilm, which refers to the bacterial tendency to grow as a confined population forming cell clusters embedded in a self-produced slimy matrix composed of extracellular polymeric substances (EPS) [1,2]. In the last decade, several studies have focused on demonstrating the involvement of Quorum Sensing (QS) in biofouling, as reviewed by Lade et al. [3,4] and Siddiqui et al. [5]. QS is defined as cell-to-cell communication enabling the bacteria to harmonize their behavior and to function as a coordinated social cluster. QS, which was first described by Fuqua et al. [6] as the bacterial capability to express certain phenotypes only when a certain cell density threshold is reached, is actually based on the ability of bacteria to produce, release, assess and respond to chemical signals called autoinducers. Three different types of autoinducers have been identified to date: $N$-acyl-L-homoserine lactones (acyl-HSLs or AHLs) for Gram-negative communication, autoinducing peptides (AIPs) for Gram-positive bacteria and furanosyl borate diesters known as AI-2 signals for interspecies communication.

In MBRs, the Gram-negative proteobacteria phylum was demonstrated to be the most abundant among the myriad MBR-living bacteria [7-9]. Thus, the prevalent bacterial communication in MBRs is believed to be Gram-negative QS which is ensured through AHLs as autoinducers. These molecules are composed of a lactone ring and an acylated chain containing four to 18carbons as reviewed by Lade et al. [3] (Figure 1).

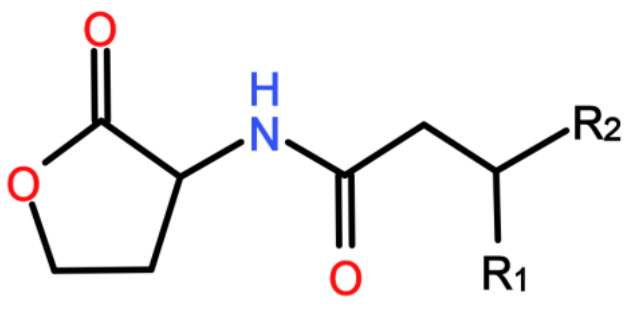

Figure 1. Structure of an N-acyl-L-homoserine lactones (AHL) molecule (R1 can be an oxo or a hydroxyl group; R2 can be a carbon chain from $\mathrm{C} 1$ to $\mathrm{C} 15)$.

AHL-mediated QS in Gram-negative bacteria is based on the biosynthesis of AHLs in the intracellular compartment, then on their accumulation both in the intracellular and the extracellular environment because of their small molecular weights. At high cell density, the extracellular concentration of AHLs increases until it reaches a threshold, beyond which bacteria can sense them and then activate the transcription of certain target genes (Figure S1) [10-14]. For more details on AHL-mediated QS for Gram-negative bacterial communication, the reader is invited to refer to the Supporting Information.

AHL-mediated QS has been proved to be involved in biofilm formation in various ways for a number of bacterial species [15-23]. A few studies on biofouling control in MBRs have focused on the potential relationship between AHLs and biofilm on the membrane. Yeon et al. [24] were the first to provide evidence of the occurrence of AHL-mediated QS in MBRs by proving the presence of different AHLs in the biocake formed on the membrane surface. This result has been confirmed [25-30] and then taken to the next step with the determination of a correlation between the AHL amount and the transmembrane pressure (TMP) level [24,29]. Hence, the occurrence of AHL-mediated QS has not only been highlighted but has also been demonstrated to be closely related to biofouling in MBRs.

With this observation, a novel biofouling mitigation strategy based on QS, i.e., Quorum Quenching (QQ), was then developed. As its name implies, QQ refers to any mechanism that can effectively disrupt QS communication [31]. In theory, QS inhibition can be achieved by targeting either the generation of AHL, the AHL molecule itself, or the AHL reception, as reviewed by Rasmussen and Givskov [32]. In the particular case of biofouling in MBRs, QQ through destruction of the AHL molecules has been the most investigated mechanism. In essence, QQ can be achieved using several QS inhibitors (QSIs), among which natural compounds, such as piper betle extract (PBE) $[29,33]$ 
and AHL-degrading enzymes or bacteria, have been preferred over synthetic QSIs for application to MBRs. To date, the degradation of AHLs is the most appreciated and the most commonly applied method for biofouling mitigation in MBRs, and this has been achieved by using either a purified QQ enzyme (porcine kidney acylase I [24,34-37]) or bacteria that produce a QQ enzyme (QQ bacteria). The former technique is referred to as "enzymatic QQ" in opposition to the latter, which is known as “bacterial QQ".

Recently, three interesting reviews have given overviews of the QS and QQ mechanisms, together with summaries of all the QSIs and all the QS-based ways to mitigate membrane biofouling in general [3-5]). However, these reviews do not plainly explain biofouling in MBRs: the links between QQ and the physical phenomena of the MBR process are not explored in depth, and the recent trends in QS-based biofouling mitigation are not fully supported by numerical data.

In the present review, special emphasis will be placed on the application of bacterial QQ to mitigate membrane biofouling in MBRs for WWT. To date, the literature reports that two major QQ bacteria have a capacity to mitigate biofouling in MBRs: Rhodococcus sp. BH4 [28] and Pseudomonas sp. 1A1 [38]. These two bacteria appear to have different modes of action to mitigate membrane biofouling, which are mostly attributable to the nature and the localization of the QQ enzymes they produce. Thus, we propose to discuss the relationship between the bacterial QQ and the MBR process here, taking the two different points of view offered by the confrontation of these two QQ bacteria. In that way, for each of these strains, the mode of action will be explained by giving details about the nature and the localization of the QQ enzyme it produces. The QQ effectiveness will be further discussed by analyzing the effects of bacterial $Q Q$ on the physical phenomena related to biofouling in MBRs at both the macroscopic and microscopic scales. Then, the effects of the MBR operating conditions on QQ effectiveness will be examined to try to highlight potentially optimal conditions for bacterial QQ application in MBRs. Finally, some concluding remarks and perspectives will be presented in the last part as directions for future research.

\section{History of Bacterial QQ}

The application of bacterial QQ by means of QQ-enzyme-producing bacteria was developed to overcome practical barriers related to the use of a purified enzyme, such as the purification costs and the loss of the enzyme activity. Oh et al. [28] were the first to experiment bacterial QQ in a lab-scale MBR. For that purpose, a batch-type MBR was supplemented with a genetically modified E. coli strain harboring the aiiA gene, coding for the production of a QQ enzyme. As a result, $30 \%$ of reduction in the TMP level was observed, and the time for the TMP to reach $25 \mathrm{kPa}$ was extended by approximately $40 \%$. The use of this recombinant $E$. coli has further led to similar results in a continuous mode, demonstrating the potential of bacterial QQ to mitigate biofouling in lab-scale MBRs. However, the use of such a recombinant strain is hardly conceivable because of its very poor chances of survival in a real MBR but also because of the need to introduce antibiotics to maintain its QQ activity. Considering the significant number of natural QQ bacteria that have been identified to date (reviewed by Czajkowski and Jafra [39] and Lade et al. [3]), the isolation of an indigenous QQ bacterium from a real MBR appeared to be the most reasonable method. Thus, Rhodococcus sp. BH4 and Pseudomonas sp. 1A1 were isolated, characterized, and tested as a QQ bacteria to mitigate membrane biofouling in MBRs.

\section{Isolation of QQ Bacteria}

Rhodococcus sp. BH4 is a Gram-positive bacterium that happens to be the first indigenous strain isolated from a real MBR for its QQ potential, using an enrichment culture method as described by Oh et al. [28]. To achieve this, activated sludge (AS) samples or biocake samples were taken from a real MBR to be further inoculated in a minimal medium containing AHLs. After incubation, the culture was transferred to a fresh minimal medium, and the transfer procedure was repeated three times to ensure the isolation of bacteria that could live with AHLs as sole carbon source. Finally, single colonies were isolated on LB agar then separately incubated in a minimal medium. Among the few 
strains isolated by this method, a strain showing high activity against C8-HSL was identified as a Rhodococcus sp. BH4 by $16 \mathrm{~S}$ rRNA sequence analysis and was finally selected for investigation its QQ potential to reduce biofouling in MBRs. Pseudomonas sp. $1 \mathrm{~A} 1$ is a Gram-negative bacterium that was further isolated from a real MBR using a minimal medium containing AHL as the sole source of carbon, according to the same enrichment method [38].

\section{Roles of Rhodococcus sp. BH4 and Pseudomonas sp. 1A1 as QQ Bacteria}

In order to identify the AHL-degrading enzyme produced by Rhodococcus sp. BH4, a genetic comparison with the known Rhodococcus erythropolis W2 was conducted and revealed the presence of the same AHL-lactonase gene [40]. Hence, the QQ activity of Rhodococcus sp. BH4 against AHLs is strongly believed to be ensured by lactonase. However, some additional research may be needed, since other strains belonging to the Rhodococcus genus have been found to produce other kinds of AHL-degrading enzymes, such as acylases and oxidoreductases [41-43].

Lactonase has the capacity to degrade AHLs by opening the lactone ring according to the enzymatic reaction presented in Figure 2. This mode of action suggests that lactonase can theoretically degrade a wide range of AHLs regardless of the acyl chain lengths and the substitutions on the third carbon (R1 group on Figure 2), evoking a non-selective QQ activity. However, it has been reported that lactonase from Rhodococcus sp. BH4 has a lower degrading activity against AHLs with an additional oxo group on the third carbon, compared to the same AHLs with no substitutions [44]. In addition, for AHLs with an oxo group, the lactonase activity increases with the length of the acyl chain, which finally suggests a greater affinity for some AHLs than for others $[40,44]$. It has been demonstrated that the lactonase activity may be impaired under acidic $\mathrm{pH}$ or at high temperature [44]. In addition, the latter study has revealed that the catalytic activity of some lactonases can be totally inhibited by the presence of certain metal ions such as $\mathrm{Cu}^{2+}$ and $\mathrm{Ag}^{+}$at $0.2 \mathrm{mM}$ [45]. Thus, when using Rhodococcus sp. $\mathrm{BH} 4$ as a lactonase-producing strain for biofouling mitigation in an MBR, it can be of great interest to check that the amounts of $\mathrm{Cu}^{2+}$ and $\mathrm{Ag}^{+}$in the MBR are below the inhibition limit of $0.2 \mathrm{mM}$ that has been reported [44]. Finally, a potential drawback of using lactonase from Rhodococcus sp. BH4 as a QQ enzyme is that the AHL degradation reaction is reversible under acidic $\mathrm{pH}$. However, the rebinding can be avoided by a chemical modification of the opened ring (substitution or reduction) [32].<smiles>[R]C([R])CC(=O)NC1CCOC1=O</smiles>

AHL<smiles>[C+]1[CH+]CC1</smiles><smiles>O</smiles>
Lactonase

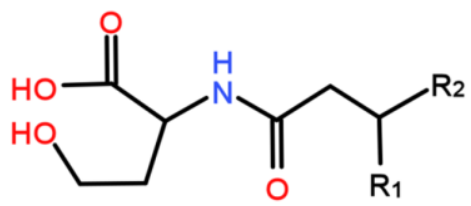

Acyl-HS

Figure 2. AHL degradation by lactonase produced by Rhodococcus sp. BH4.

For Pseudomonas sp. 1A1, a genetic analysis revealed the presence of an AHL-acylase homologue gene, which implies that the QQ activity of this strain towards AHLs is most likely ensured by an acylase [38]. This finding is consistent with a previous study investigating the QQ enzyme produced by another Pseudomonas strain (PAO1) [46].

Acylase is known to degrade AHLs by hydrolyzing the amine bond between the acyl chain and the lactone ring to produce homoserine lactones and fatty acids (Figure 3). Concerning the enzymatic activity of acylase from Pseudomonas sp. 1A1, it has been proved that the longer the acyl side chain is, the greater is the degradation rate, for both substituted and unsubstituted AHLs ranging from $\mathrm{C} 6$ to $\mathrm{C} 12$ [38]. Similar results have been obtained when characterizing an acylase from Anabaena sp. PCC7120, which confirms that the acylase activity depends on the side chain length [47]. Furthermore, it is highly probable that the activity of acylase from Pseudomonas sp. $1 \mathrm{~A} 1$ is dependent on $\mathrm{pH}$ and temperature, as has been demonstrated for a purified acylase, porcine kidney acylase [48]. 


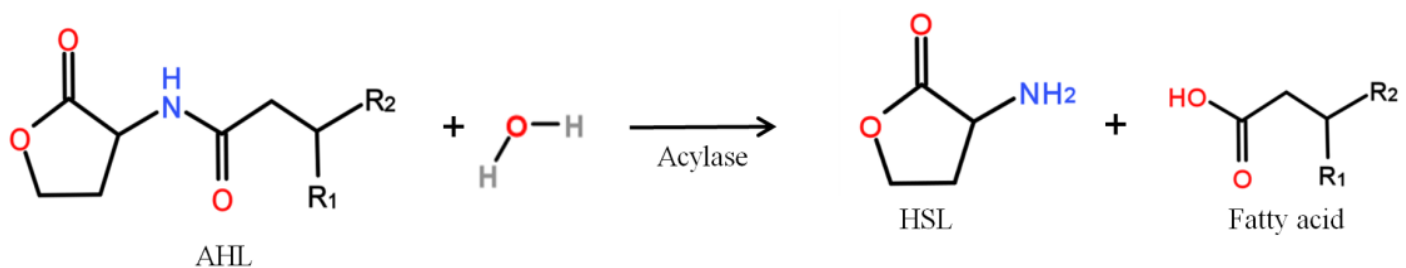

Figure 3. AHL degradation by acylase produced by Pseudomonas sp. 1A1.

\section{Methods for Entrapping QQ Bacteria in MBRs}

After the identification of these two QQ bacteria, their implementation in MBRs was carried out to assess their potential to mitigate biofouling by interfering with AHL signal molecules. For that purpose, different entrapping methods were used, in order to avoid loss of cells with the withdrawal of excess sludge from the MBR, as well as to protect them against the attack of other microorganisms cohabiting in the MBR, QQ bacteria were added using three entrapping methods: (i) microbial vessels for entrapping Rhodococcus sp. BH4 and Pseudomonas sp. 1A1 (ii) sodium alginate beads and (iii) a Rotating Microbial Carrier Frame (RMCF), for Rhodococcus sp. BH4.

(i) Microbial vessels were designed to maintain the QQ bacteria immobilized using a porous material permitting the free diffusion of AHLs and nutrients through the vessel. For example, Oh et al. [28] used a module composed of hollow, 10-cm long polyethylene (PE), fibers to encapsulate the Rhodococcus sp. BH4 cells (Figure 4a). The module was then submerged and held in a fixed place in the MBR. The initial amounts of Rhodococcus sp. BH4 cells inserted in microbial vessels ranged from approximately 130 to $450 \mathrm{mg} / \mathrm{L}$ of the total working volume [28,40,49]. The volume of the vessel itself represented less than $0.08 \%$ of the MBR volume. For Pseudomonas sp. 1A1, two types of materials were used for these vessels: PE and ceramic. As for Rhodococcus sp. BH4, Cheong et al. [38] made PE vessels using microporous HF $(0.4 \mu \mathrm{m})$. They also designed a ceramic microbial vessel (CMV) consisting of a monolithic microporous module $(0.45 \mu \mathrm{m})$ with a total length of $10 \mathrm{~cm}$ and composed of several lumens into which the cells were injected using a sterile syringe (Figure 4c). The initial quantities of Pseudomonas sp. 1A1 cells tested varied from approximately 200 to $700 \mathrm{mg} 1 \mathrm{~A} 1 / \mathrm{L}$ of the total working volume.

(ii) Sodium alginate beads were only used for entrapping Rhodococcus sp. BH4. They were prepared by dripping a mixture of a Rhodococcus sp. BH4 suspension and a sodium alginate solution through a nozzle into a $\mathrm{CaCl}_{2}$ solution to obtain spherical Cell Entrapping Beads (CEBs) as described by Kim et al. [25] (Figure 4b). In that case, the amount of Rhodococcus sp. BH4 entrapped in the beads was around $6 \mathrm{mg} \mathrm{BH} 4 / \mathrm{g}$ sodium alginate. Kim et al. [50] further developed macrocapsules by coating the CEBs with a microporous polymer layer for better resistance to harsh conditions resulting from the use of real WW. Recently, Lee et al. [26] developed QQ beads made of a mixture of polyvinyl alcohol and sodium alginate to reinforce their stability in real WW. The beads were then inserted into the MBR where they could move freely.

(iii) Recently, an RMCF has been developed as a new entrapping technology for Rhodococcus sp. BH4, using a polycarbonate frame and four cubbyholes covered with a polyvinylidene fluoride (PVDF) microfiltration membrane, and packed with a Rhodococcus sp. BH4 suspension using a syringe. The RMCF was then set into the MBR similarly to a mechanical stirring device [51]. 


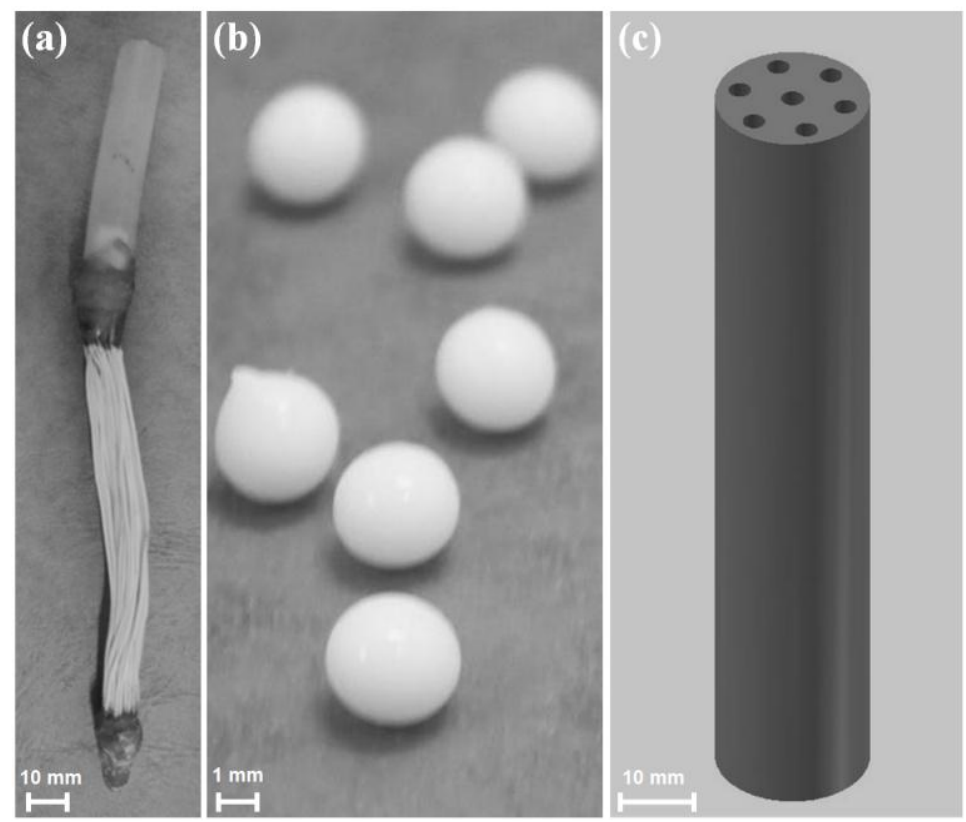

Figure 4. (a) Polyethylene (PE) microbial vessel; (b) sodium alginate beads for Rhodococcus sp. BH4 entrapment and (c) ceramic microbial vessel (CMV) for Pseudomonas sp. 1A1 entrapment.

\section{Localization of the Activity of the QQ Bacteria in the MBR}

Measuring the enzymatic activities of the supernatant and the pellets from the same Rhodococcus sp. BH4 suspension sample has revealed that the QQ activity of Rhodococcus sp. BH4 is based on the production of an intracellular AHL-lactonase (endo-enzyme), which indicates that the enzymatic degradation of AHLs takes place inside the Rhodococcus sp. BH4 cells [40]. This implies that, when Rhodococcus sp. BH4 is implemented in an MBR for membrane biofouling control, the AHLs from either the mixed liquor or the biocake on the membrane are transported by convection towards the entrapping element, diffuse through this porous element towards the Rhodococcus sp. BH4 cells and then through the cell membrane to be hydrolyzed in their intracellular compartment (Figure 5). When the microbial vessel is used as an entrapping element, the Rhodococcus sp. BH4 cells are held in a fixed place in the MBR and the convective forces created by the aeration and the suction are expected to drive the AHLs towards the immobilized Rhodococcus sp. BH4 cells. The latest technology for encapsulating the QQ bacteria (RMCF) is not represented in Figure 5 but it is noteworthy that the rotation motion of this module is believed to prevent the sedimentation of cells in the module and to generate additional shear forces in the MBR, which may promote AHL transport. Finally, in the case of beads, it can be assumed that the free movement of the beads in the MBR enhances the probability that AHLs will encounter the Rhodococcus sp. BH4 cells. Nevertheless, the complex structure of the sodium alginate core could slow down the diffusion of AHLs through the beads. Therefore, the localization of the QQ activity is key information that can significantly impact the choice of one of these entrapping techniques. In the following, the possible impact of the different entrapping techniques on the effectiveness of $Q Q$ to mitigate biofouling will be discussed. 


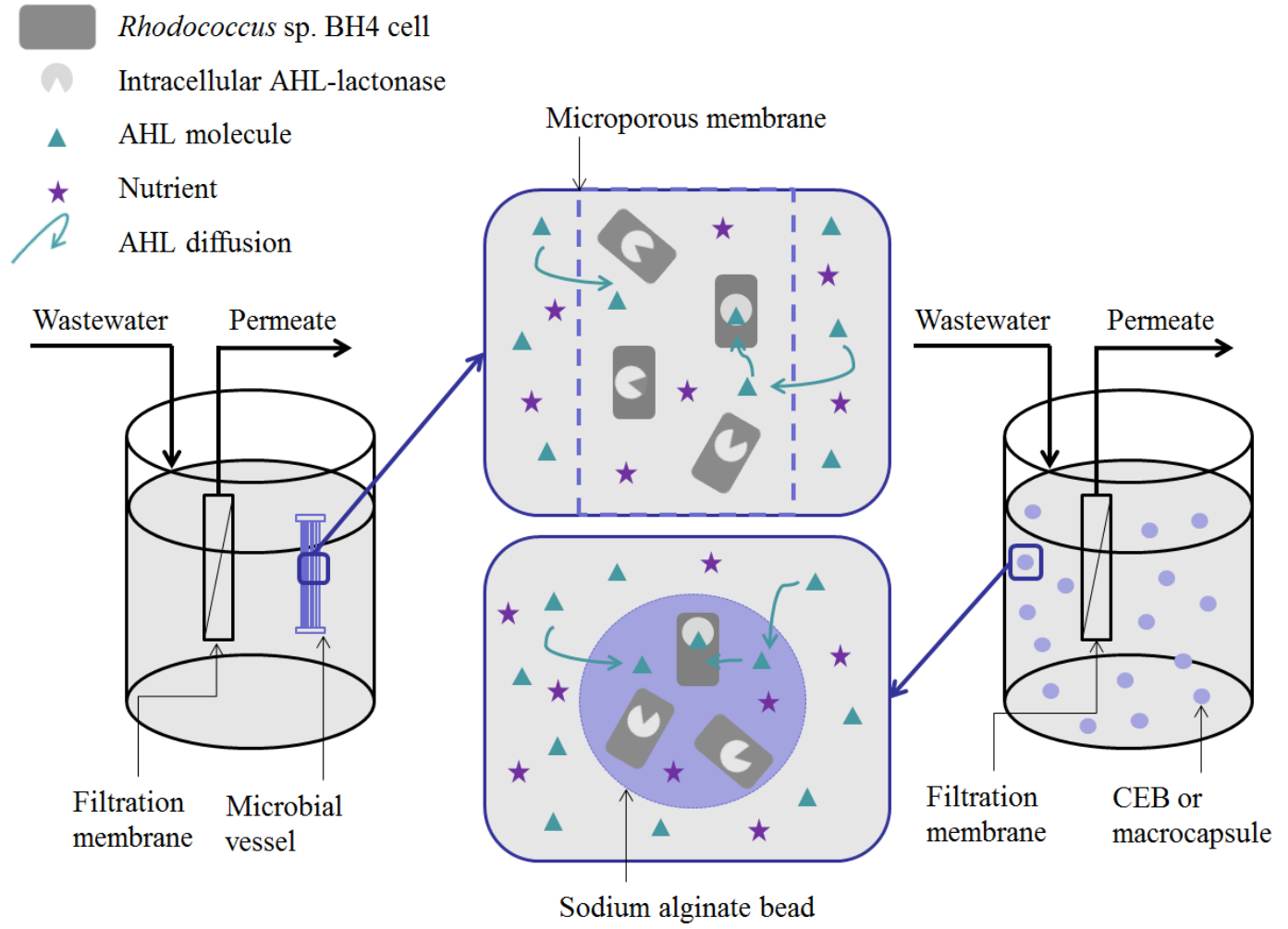

Figure 5. Localization of the Quorum Quenching (QQ) activity of Rhodococcus sp. BH4 entrapped in a microbial vessel or sodium alginate beads in a lab-scale membrane bioreactor (MBR).

Unlike lactonase from Rhodococcus sp. BH4, acylase produced by Pseudomonas sp. 1A1 has been proved to be an exo-enzyme having extracellular activity [38]. This finding has been further reinforced by the fact that acylases released from Pseudomonas sp. 1A1 continued to accumulate in the extracellular environment even when the concentration of dead cells started to increase. Thus, the acylase produced by Pseudomonas sp. 1A1 is believed to spread freely out of the cells to bind to and hydrolyze AHLs everywhere in the reactor or on the membrane surface as well as inside or outside the entrapping device (Figure 6).

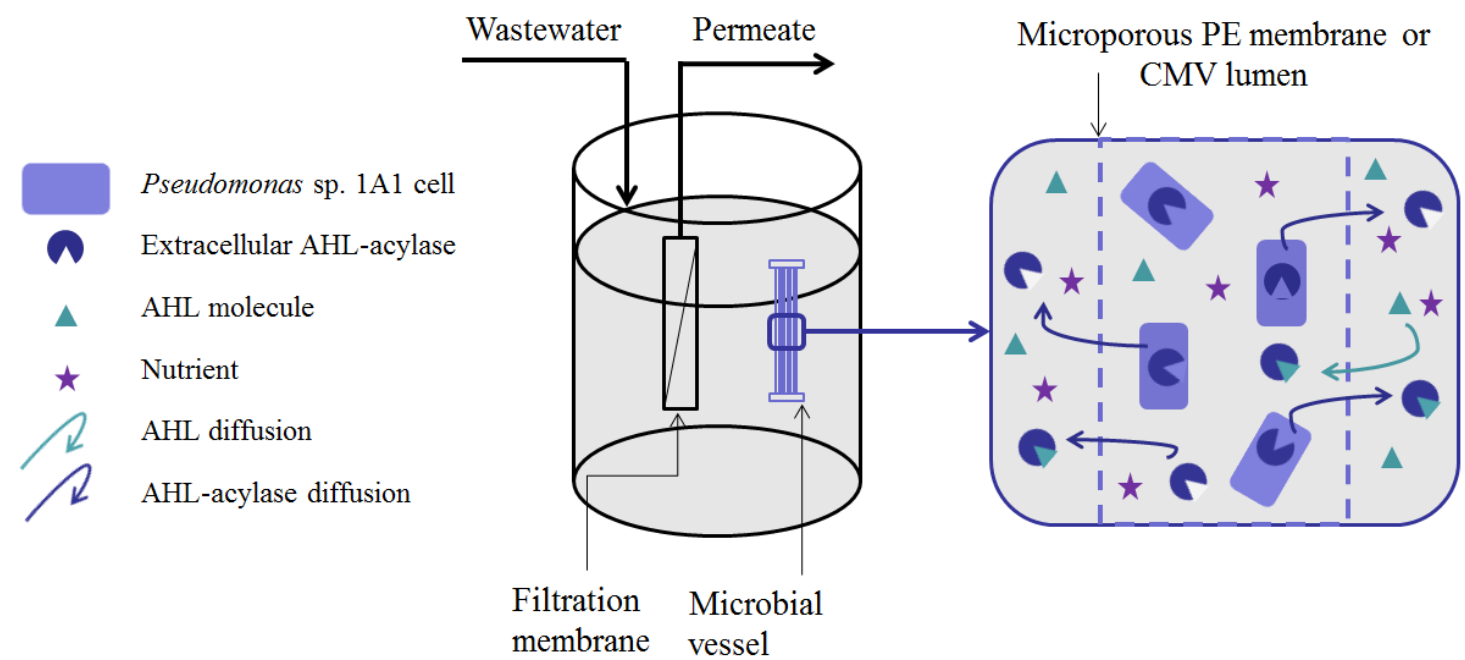

Figure 6. Localization of the QQ activity of Pseudomonas sp. 1A1 entrapped in a microbial vessel in a lab-scale MBR. 


\section{Performance of the Bacterial QQ-MBR}

In order to assess the Rhodococcus sp. BH4 capacity to mitigate biofouling in MBRs through a QQ activity, entrapped cells were introduced in different lab-scale MBRs (working volume $<5 \mathrm{~L}$ ), a semi-pilot MBR (working volume of $35 \mathrm{~L}$ ) and pilot-scale MBRs (working volume $\geq 80 \mathrm{~L}$ ) operated in a continuous mode. The MBRs were inoculated with AS from WWT plants, and hollow fibers (HF) or Flat Sheets (FS) were used to ensure the WW filtration. In parallel to these QQ MBRs, control MBRs were systematically run using the entrapping elements with no Rhodococcus sp. BH4 cells inside (vacant vessel, vacant beads or vacant RMCF) to maintain exactly the same hydrodynamic conditions. Table 1 gathers together all the studies on the effectiveness of Rhodococcus sp. BH4 in reducing biofouling in MBRs.

Concerning Pseudomonas sp. 1A1, its potential to mitigate biofouling has been assessed and is shown in Table 2. All experimental data were gathered from the operation of a lab-scale control or QQ-MBR (working volume $5 \mathrm{~L}$ ) running in a continuous mode, in which a filtration membrane module (PVDF HF) was submerged. Various factors were compared between a control-MBR without Pseudomonas sp. 1A1 cells in the vessels and a QQ-MBR with the cells.

A wide variability can be observed in the way results are expressed in these studies. Hence, we propose to standardize these results in terms of percentages of the control MBR performance, so as to better highlight the contribution of QQ to biofouling reduction. The calculation used to convert results into percentages is presented in Equation (1).

$$
P \%=-\frac{M_{\text {control MBR }}-M_{Q Q M B R}}{M_{\text {control MBR }}} \times 100
$$

$P \%$ is the standardized result in percentages; $\mathrm{M}$ is one of the properties measured to characterize biofouling; the minus sign (-) stands for the reduction of biofouling by QQ. 
Table 1. Effect of Rhodococcus sp. BH4-mediated Quorum Quenching on membrane biofouling mitigation in MBRs inoculated with activated sludge (AS), under continuous mode and using hollow fibers (HF) or flat sheet (FS) membrane as the filtration module.

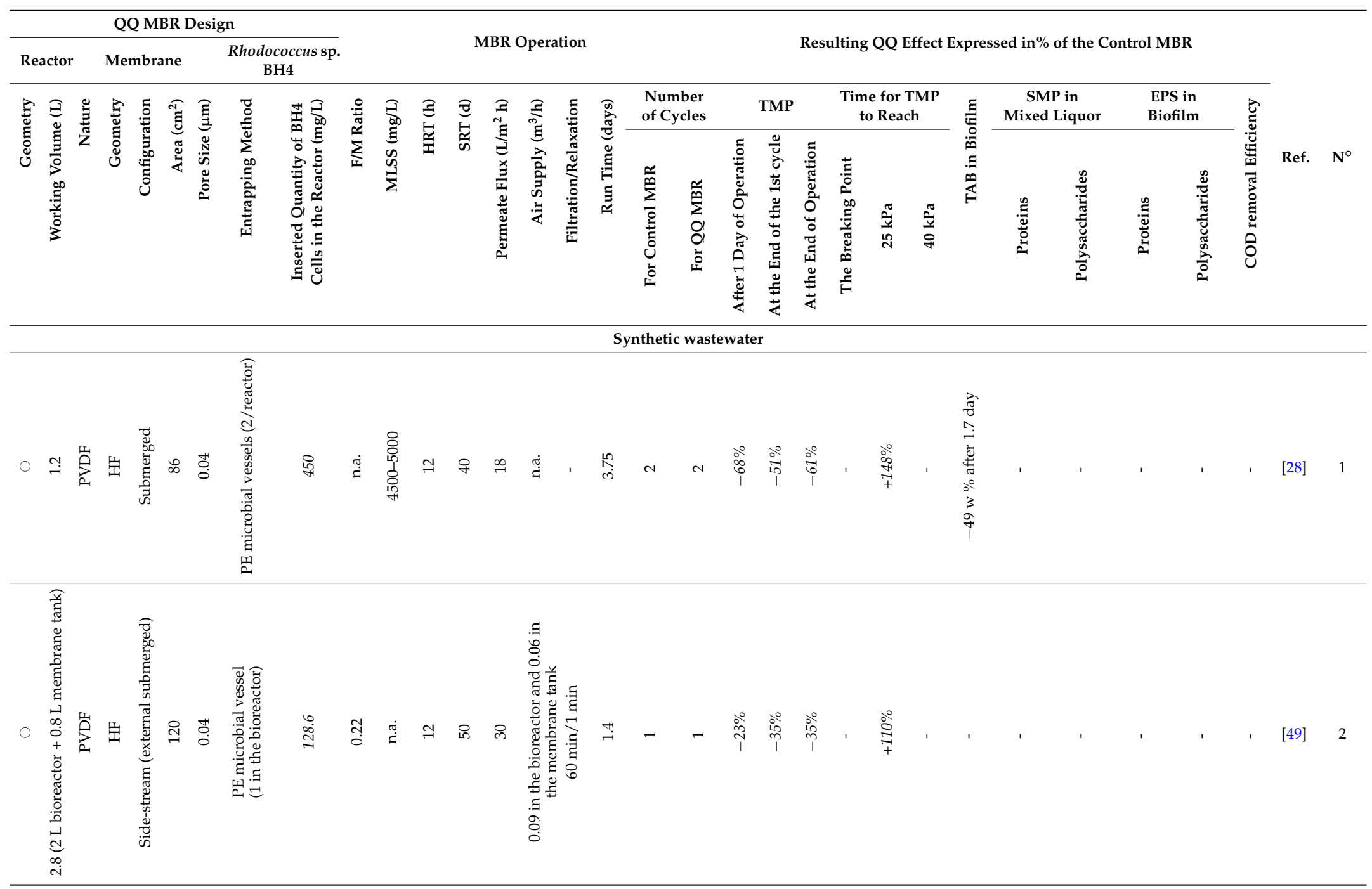


Table 1. Cont.

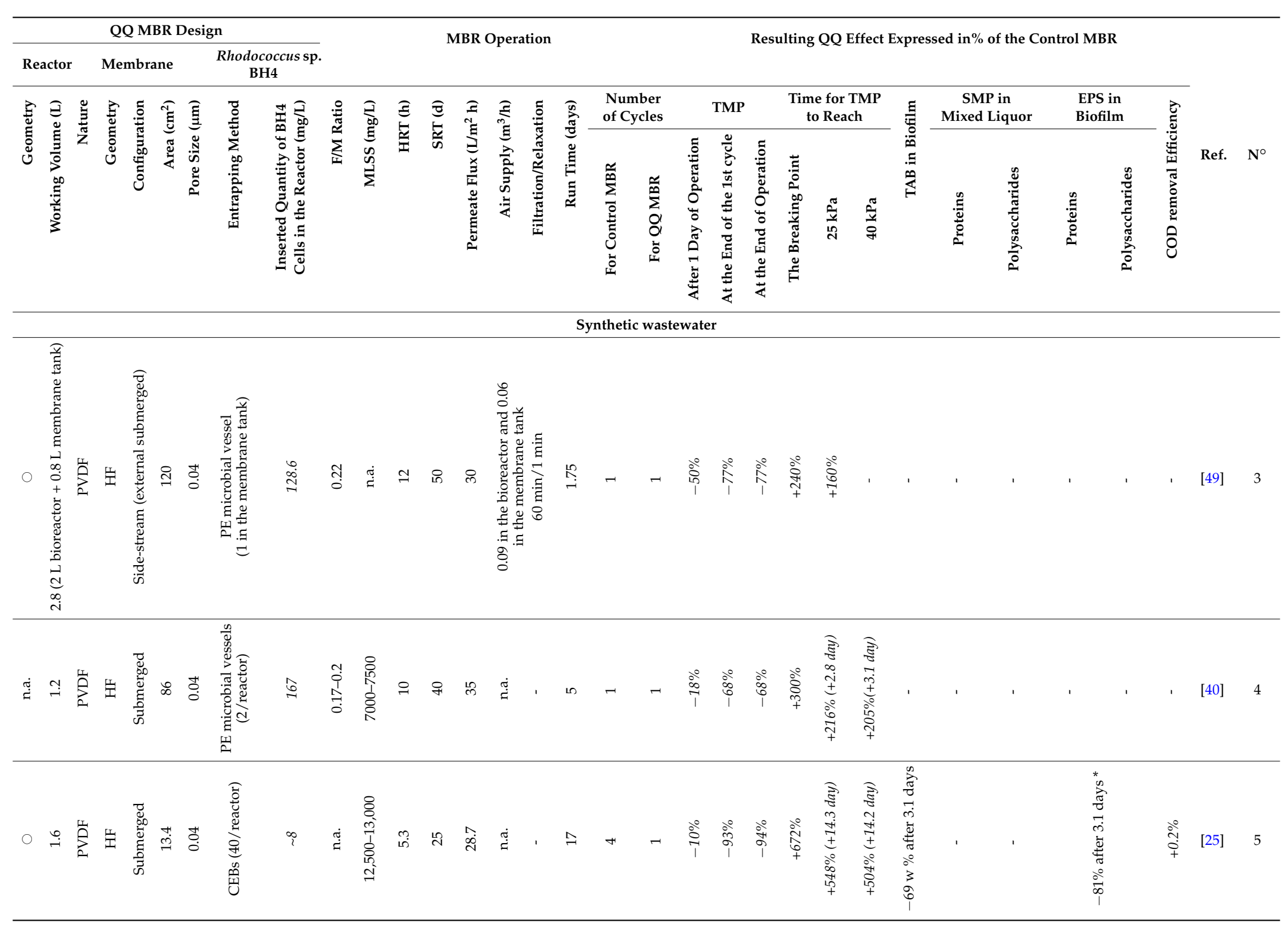


Table 1. Cont.

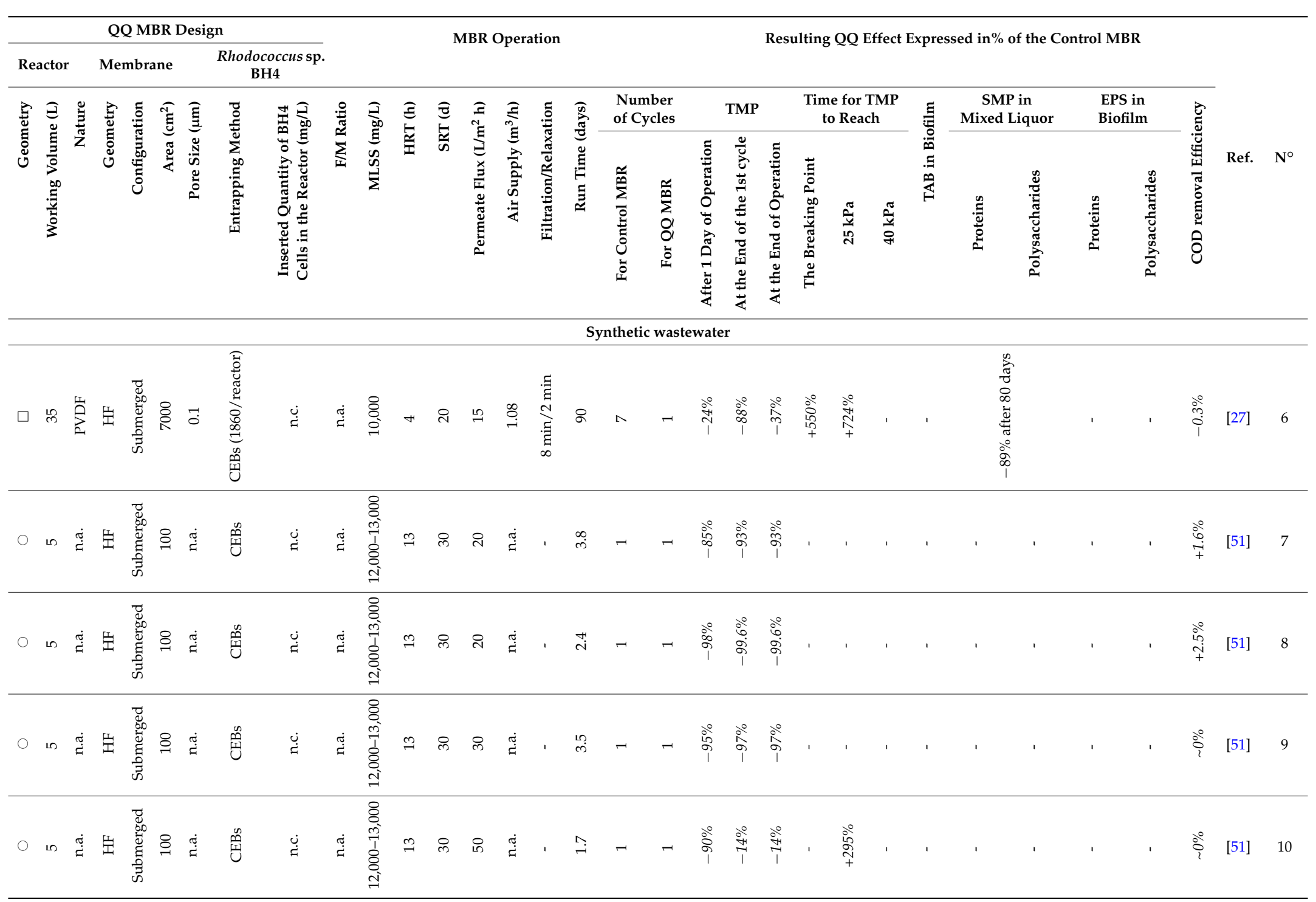


Table 1. Cont.

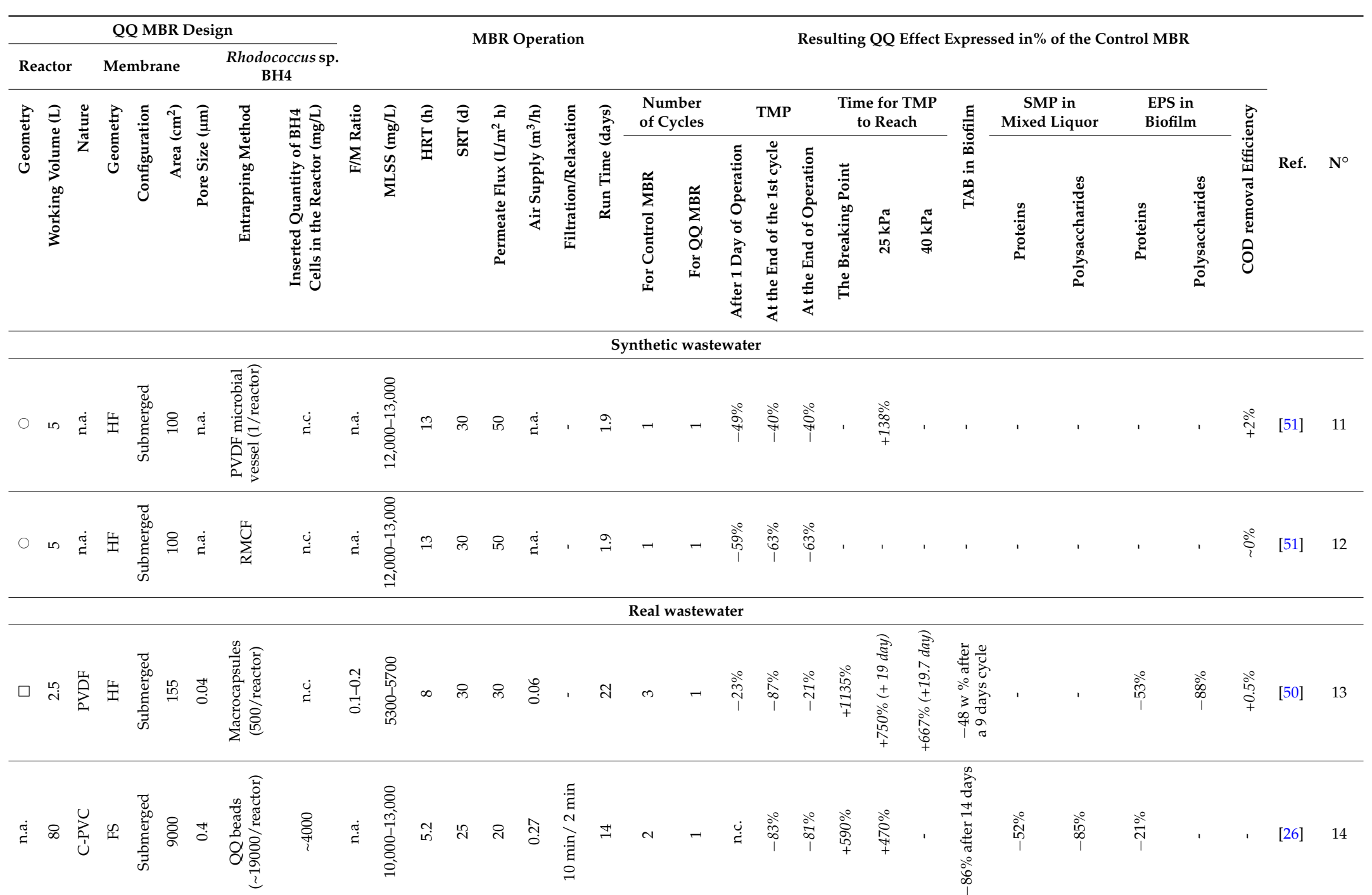

○: Cylindrical; $\square$ : Parallelepiped; Numbers: Taken from the literature; Numbers: Calculated with the data provided in the literature; n.a./-: Not available data; n.c.: Not calculable value with the data provided. 
Table 2. Effect of Pseudomonas sp. 1A1-mediated Quorum Quenching on membrane biofouling mitigation in MBRs inoculated with AS, under continuous mode and using submerged polyvinylidene fluoride (PVDF) hollow fibers as the filtration module.

\begin{tabular}{|c|c|c|c|c|c|c|c|c|c|c|c|c|c|c|c|c|c|c|c|c|c|c|c|c|c|c|c|}
\hline \multicolumn{7}{|c|}{ MBR Design } & \multirow{4}{*}{ 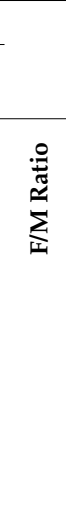 } & \multirow{4}{*}{ 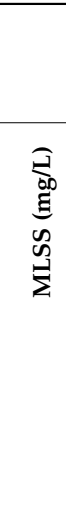 } & \multirow{2}{*}{\multicolumn{4}{|c|}{ MBR Operation }} & \multirow{2}{*}{\multicolumn{13}{|c|}{ Resulting QQ Effect Expressed in \% of the Control MBR }} & \multirow[b]{4}{*}{ Ref. } & \multirow[b]{4}{*}{ - $\mathbf{N}$} \\
\hline & ictor & & embra & & Pseud & $\begin{array}{l}\text { nonas sp. } \\
\text { A1 }\end{array}$ & & & & & & & & & & & & & & & & & & & & & \\
\hline \multirow{2}{*}{ 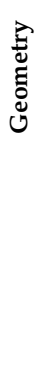 } & \multirow{2}{*}{ 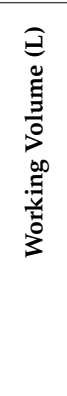 } & \multirow{2}{*}{ 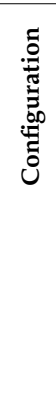 } & \multirow{2}{*}{ 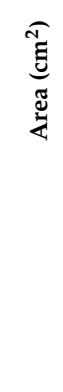 } & \multirow{2}{*}{ 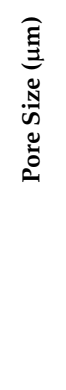 } & \multirow{2}{*}{ 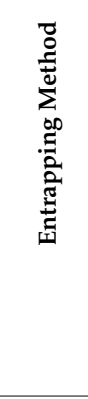 } & \multirow[b]{2}{*}{ 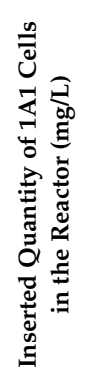 } & & & \multirow{2}{*}{ 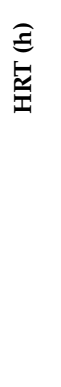 } & \multirow{2}{*}{$\begin{array}{l}\hat{\sigma} \\
\hat{\sigma} \\
\tilde{\omega}\end{array}$} & \multirow{2}{*}{ 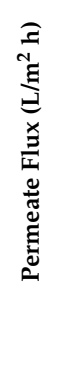 } & \multirow{2}{*}{ 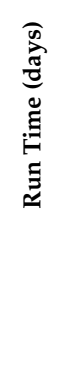 } & \multicolumn{2}{|c|}{$\begin{array}{c}\text { Number of } \\
\text { Cycles }\end{array}$} & \multicolumn{3}{|c|}{ TMP } & \multicolumn{3}{|c|}{$\begin{array}{c}\text { Time for TMP } \\
\text { to Reach }\end{array}$} & \multirow{2}{*}{ 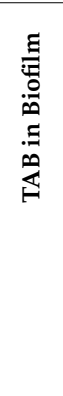 } & \multicolumn{2}{|c|}{$\begin{array}{l}\text { SMP in Mixed } \\
\text { Liquor }\end{array}$} & \multicolumn{2}{|c|}{$\begin{array}{l}\text { EPS in } \\
\text { Biofilm }\end{array}$} & & \\
\hline & & & & & & & & & & & & & 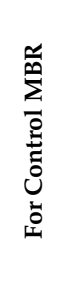 & 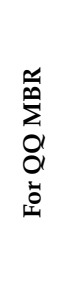 & 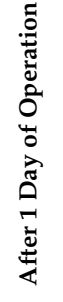 & 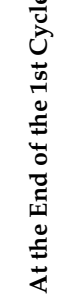 & 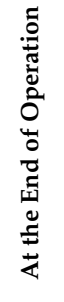 & 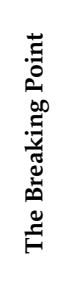 & $\frac{\pi}{\frac{\pi}{\pi}}$ & $\frac{\tilde{g}}{g}$ & & 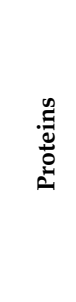 & 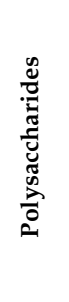 & 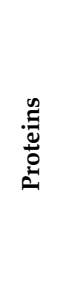 & 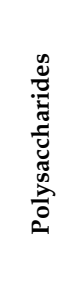 & & \\
\hline O & $\stackrel{\operatorname{Ln}}{\mathrm{i}}$ & 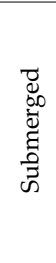 & 点 & 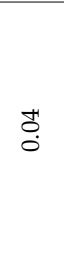 & 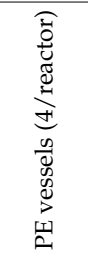 & నิ & $\begin{array}{l}\text { ה̃ } \\
0 \\
1 \\
\text { กิ } \\
0\end{array}$ & $\begin{array}{l}8 \\
8 \\
\infty \\
0 \\
0 \\
0 \\
1\end{array}$ & $\infty$ & §ి & $\stackrel{\stackrel{2}{N}}{2}$ & $\stackrel{\infty}{\wedge}$ & r & $\mathrm{n}$ & $\stackrel{\circ}{i}$ & $\stackrel{\circ}{\stackrel{1}{1}}$ & ஓे & $\begin{array}{l}\stackrel{0}{0} \\
\stackrel{\infty}{+}\end{array}$ & 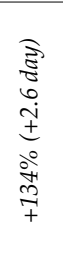 & 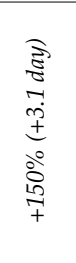 & ' & ' & ' & ' & , & [38] & 1 \\
\hline O & $\stackrel{\circ}{\dot{m}}$ & 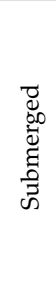 & $\stackrel{ }{\text { సे }}$ & ${ }_{0}^{0}$ & 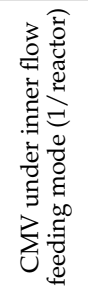 & $\begin{array}{l}\infty \\
\stackrel{2}{1}\end{array}$ & 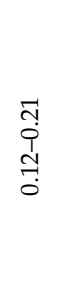 & 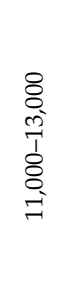 & $\bullet$ & 8 & के & $\vec{i}$ & $\neg$ & - & $\stackrel{\stackrel{\circ}{i}}{i}$ & $\stackrel{\circ}{i}$ & $\stackrel{\circ}{i}$ & & ' & , & $\begin{array}{l}\circ 0 \\
0 \\
0 \\
\hat{0} \\
1\end{array}$ & ' & ' & ' & , & [52] & 2 \\
\hline O & $\ddot{\rho}$ & 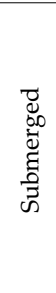 & $\stackrel{ }{\lambda}$ & 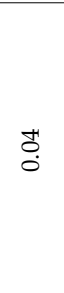 & 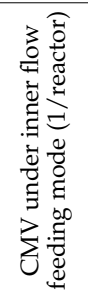 & 文 & 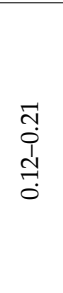 & 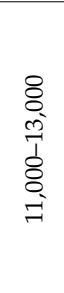 & 6 & 8 & $\stackrel{\stackrel{2}{ }}{2}$ & $\ddot{\sigma}$ & - & $r$ & 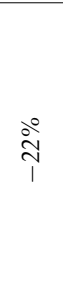 & $\stackrel{8}{i}$ & $\stackrel{8}{i}$ & ' & ' & ' & ' & ' & ' & ' & 1 & [52] & 3 \\
\hline
\end{tabular}


Table 2. Cont.

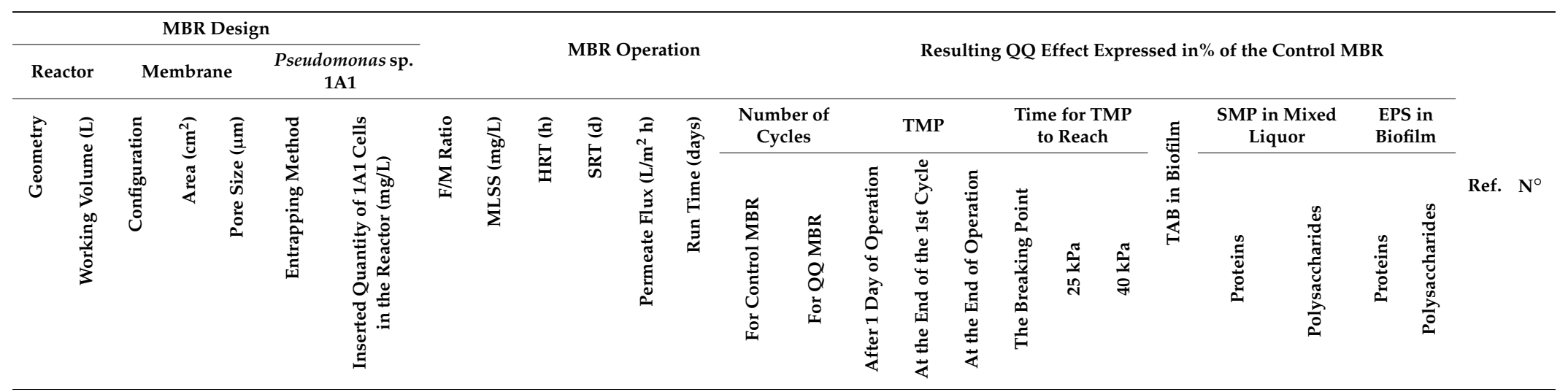

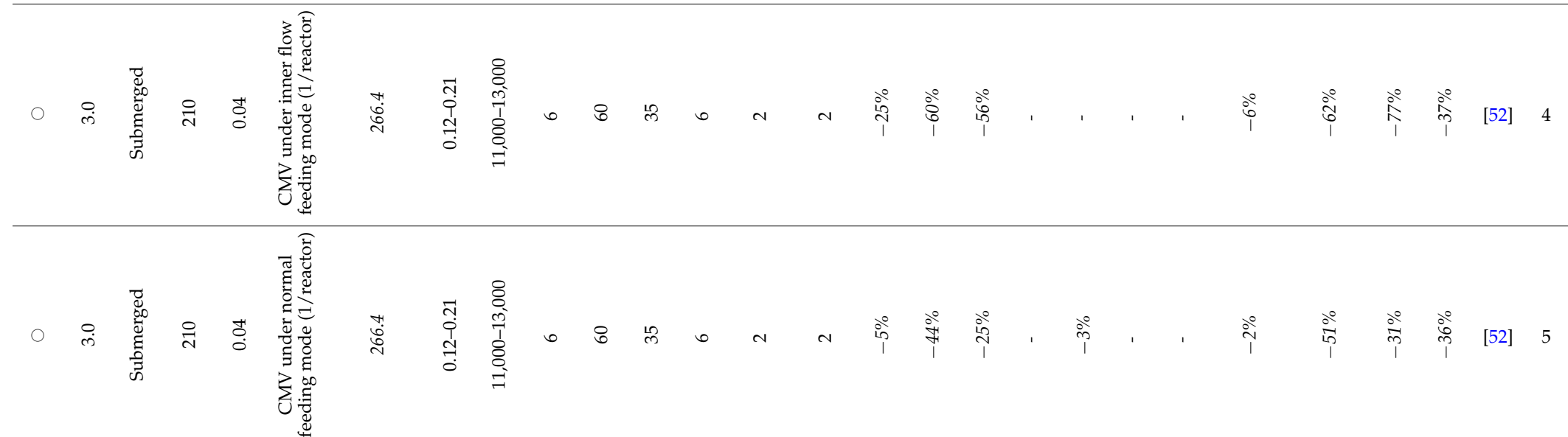

○: Cylindrical; Numbers: Taken from the literature; Numbers: Calculated with the data provided in the literature; n.a./-: Not available data; n.c.: Not calculable value with the data provided. 


\section{Effect of Bacterial QQ on the MBR Performance at Macroscopic Scale}

The effect of QQ on the MBR performance at macroscopic scale is discussed here in terms of TMP, characteristics of the mixed liquor, and biodegradation efficiencies.

The TMP was chosen because it is without any doubt the most monitored property in studies of biofouling in MBRs, most likely because it is an excellent indicator of biofouling and it can be easily measured continuously during the MBR operation, providing key information on the biofouling kinetics. For these reasons, all the studies reporting the effectiveness of QQ to mitigate biofouling are at least partly based on the comparison of the TMP profiles. Before giving numerical results, we illustrate the general shape of the TMP profile in MBRs, then the possible modifications resulting from the implementation of bacterial $Q Q$ and the information that can be deduced from the comparison of the two shapes.

Figure 7 presents a schematic illustration of the TMP profiles during MBR operation at constant flux. The fouling phenomenon is now recognized by the MBR community as a three-stage process. Initially, a short-term increase in TMP is observed, from point A to point B, and can probably be attributed to initial pore blocking and the adsorption of solutes from the mixed liquor. Next, a slow long-term rise takes place between points $B$ and $C$, and is due to the progressive deposition of biosolids (cells and microbial flocs) on the membrane surface and the progressive formation of biofilm. Finally, at point $C$, called the breaking point, a striking increase, called the TMP jump, indicates a severe loss of permeability [53-55]. The occurrence of the TMP jump depends on the operating conditions and is believed to be caused by sudden changes in local flux or in the biocake architecture and EPS composition [55-60]. Once point D is reached, the filtration process is stopped and the membrane is either cleaned with a view to reusing it, or changed. The time at which point $\mathrm{D}$ is reached is defined as a cycle, and several cycles usually take place during an MBR run.

With the implementation of QQ bacteria to reduce biofouling in MBRs, the second stage of the TMP rise-up is expected to be significantly slowed down from point $B$ to point $C^{\prime}$, and the occurrence of the TMP jump (at the breaking point) would thus be delayed (Figure 7). Moreover, the TMP jump from point $C^{\prime}$ to point $\mathrm{D}^{\prime}$ could be expected to be attenuated, indicating that the addition of $Q Q$ bacteria could lead to modified biofouling behavior with temporal and spatial variations in both the progressive biofouling stage and the TMP jump stage. Nevertheless, one particular case could be that the TMP jump in the QQ MBR ( $C^{\prime} \mathrm{D}^{\prime}$ section in Figure 7) was parallel to that in the control MBR (CD section in Figure 7), which could imply that $Q Q$ only slows down the progressive biofouling stage with no major changes in the TMP jump stage.

In the studies reported in Tables 1 and 2, the initial TMP did not exceed $10 \mathrm{kPa}$ (it ranged from approximately 3 to $10 \mathrm{kPa}$ ). For all these studies, it was possible to identify the kind of TMP evolution presented in Figure 7. However, the first short-term increase stage (AB section in Figure 7), which takes place relatively quickly, was not clearly identifiable, especially for the studies carried out in the long-term operation.

In order to know which of these stages is the most affected by bacterial $Q Q$, we chose to distinguish between the effect on the progressive biofouling stage (section $B C^{\prime}$ in Figure 7) and the effect on the TMP jump (section $C^{\prime} D^{\prime}$ in Figure 7).

Hence, the analysis of the TMP profiles with the latter approach, combined with the characterization of the mixed liquor and the biodegradation efficiencies, are expected to provide information about the direct effects of QQ on the physical phenomena in the MBR at macroscopic scale. 


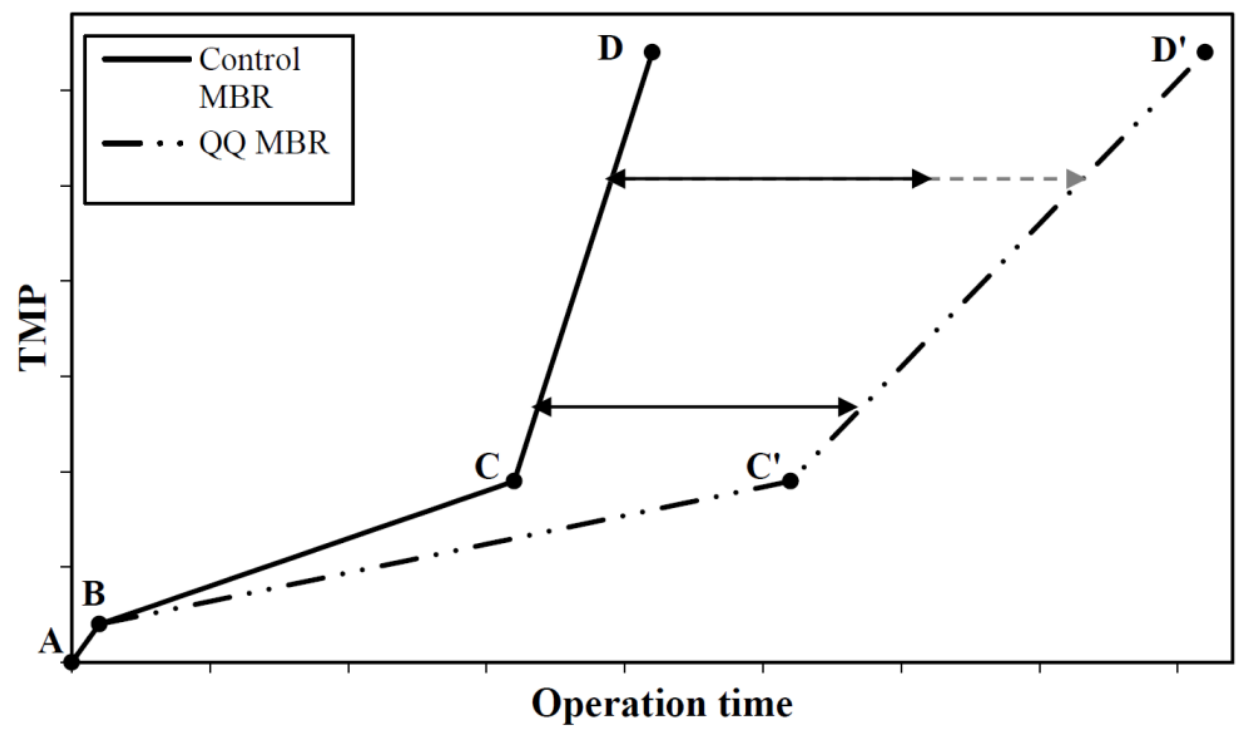

Figure 7. Schematic representation of the TMP profiles obtained in control MBR (solid line) and QQ MBR (dotted line).

\subsection{Effect on the Progressive Biofouling Stage}

For the assessment of the bacterial QQ effect on the progressive biofouling stage, it may be interesting to take into account the vertical gap between the $\mathrm{BC}$ and $\mathrm{BC}^{\prime}$ sections at the arbitrary time of 1 day (Figure 7). This time has been chosen because it is the time by which the steady progressive biofouling stage was set in all the studies considered in Tables 1 and 2. This gap would then represent the TMP reduction induced by QQ after 1 day of MBR operation.

After 1 day of operation, a significantly reduced TMP value was noted (references $n^{\circ} 1$ to 3 and $\mathrm{n}^{\circ} 7$ to 12 in Table 1) with more than $50 \%$ reduction. On the other hand, for the studies monitoring longer operation times (references $n^{\circ} 4$ to 6 and $n^{\circ} 13$ and 14 in Table 1), the TMP reduction was less pronounced, with less than $25 \%$ reduction. With these results, it appears that Rhodococcus sp. BH4-mediated QQ effectively slows down the progressive biofouling stage, which indicates that Rhodococcus sp. BH4 probably expresses its QQ activity from the very early phase of the MBR operation (during the first day). However, this effect is less visible for longer operation times.

For Pseudomonas sp. 1A1, the TMPs measured in QQ-MBRs were between $15 \%$ and $25 \%$ lower than that in control-MBRs, after 1 day of operation (references $n^{\circ} 1$ to 4 in Table 2). These values indicate that Pseudomonas sp. 1A1-mediated QQ has a marked effect on the progressive biofouling stage, which means that the Pseudomonas sp. $1 \mathrm{~A} 1 \mathrm{QQ}$ activity starts relatively early in the MBR operation, slowing down the progressive biofouling stage. Nevertheless, it seems that this effect is less pronounced than that of Rhodococcus sp. BH4.

\subsection{Effect on the TMP Jump}

For the evaluation of the Rhodococcus sp. BH4-mediated QQ effect on the TMP jump, two criteria have been chosen. The first criterion is the comparison of the times $t$ and $t^{\prime}$ corresponding to the times for reaching the breaking points $C$ and $C^{\prime}$, respectively (Figure 7), which provide a quantified information about the TMP jump postponement. The second criterion is the comparison of the slopes of the sections $\mathrm{CD}$ and $\mathrm{C}^{\prime} \mathrm{D}^{\prime}$ which were calculated with the points at $25 \mathrm{kPa}$ and $40 \mathrm{kPa}$ that were found to belong to the TMP jump stage for long-term operation.

The analysis of the breaking points according to the first criterion reveals that the time at which the TMP jump occurs is successfully delayed with the implementation of Rhodococcus sp. BH4-mediated $\mathrm{QQ}$, by at least $240 \%$ (corresponding approximately to a threefold postponement) [49] (references $\mathrm{n}^{\circ} 3$ to 6 and $n^{\circ} 13$ and 14 in Table 1). 
For the second criterion, only the long-term MBR operations with running times ranging from 17 to 90 days were taken into account (references $n^{\circ} 5,6$ and 13 in Table 1 ) since the filtration in shorter operations is usually stopped before (or right after) the breaking point is reached. The time delays to reach the two points of $25 \mathrm{kPa}$ and $40 \mathrm{kPa}$ with QQ were approximately the same for Kim et al. [25,50] (references $\mathrm{n}^{\circ} 5$ and 13 in Table 1), which refers to similar slopes (around $160 \mathrm{kPa} / \mathrm{day}$ for Kim et al. [25] and $25 \mathrm{kPa}$ /day for Kim et al. [50]) for the sections CD and C'D' (Figure 7). This indicates that Rhodococcus sp. BH4-mediated QQ seems to have no effect on the TMP jump stage in these two cases. In contrast, for Lee et al. [26] and Maqbool et al. [27] (references $n^{\circ} 6$ and 14 in Table 1), the point of $40 \mathrm{kPa}$ was not actually reached and a less pronounced TMP jump was recorded (data not shown), which indicates a substantial effect of Rhodococcus sp. BH4-mediated QQ on the TMP jump.

Studying the effect of Rhodococcus sp. BH4-mediated QQ on the TMP jump in addition to its effect on the progressive biofouling stage may give interesting insight into how the QQ effectiveness might evolve over time in the MBR. According to these results, it seems that Rhodococcus sp. BH4-mediated QQ tends to be globally more effective in inducing modifications of the TMP profile during the first progressive biofouling stage than during the TMP fast jump stage, which could be attributed to a potential loss of the QQ effectiveness. Another potential explanation could be that another type of QS-controlled biofouling (e.g., AI-2-controlled QS for interspecies communication), against which the Rhodococcus sp. BH4 cells have no effect, becomes predominant over the AHL-controlled one. However, further research would be needed to clarify these assumptions. All these results taken together with the number of cycles of the control MBRs compared to the QQ MBRs clearly indicate that the implementation of Rhodococcus sp. BH4-mediated QQ substantially reduces the membrane cleaning frequency.

Cheong et al. [38,52] investigated the effectiveness of Pseudomonas sp. 1A1 to mitigate biofouling in MBRs for running times ranging from 6 to 13 days. Concerning the comparison of the times $t$ and $t^{\prime}$ at which the breaking points $C$ and $C^{\prime}$ were reached for the control and the QQ MBR, respectively (Figure 7), the time elapsing before the TMP jump was observed to increase by $180 \%$ (corresponding to an almost threefold postponement) (reference $\mathrm{n}^{\circ} 1$ in Table 2). When comparing the slopes corresponding to the TMP jump sections CD and $\mathrm{C}^{\prime} \mathrm{D}^{\prime}$ (Figure 7), the times necessary to attain the pressures of $25 \mathrm{kPa}$ and $40 \mathrm{kPa}$ were both seen to be delayed by approximately 3 days (reference $\mathrm{n}^{\circ} 1$ in Table 2). Although these results reveal that Pseudomonas sp. 1A1-mediated QQ does indeed have an effect on biofouling, more research is needed to unravel how Pseudomonas sp. 1A1 mitigates biofouling in MBRs and how its effectiveness evolves over time.

\subsection{Effect on the Mixed Liquor Characteristics}

It is important to evaluate the effect of QQ on the mixed liquor characteristics, particularly in terms of EPS and AHL amounts, since these are good indicators of biofouling.

EPS are well-known to be closely related to biofouling in MBRs since they are the "glue" that holds the biofilm cell clusters attached to the membrane [2]. In other words, a noticeable increase in the amount of EPS in the MBR is correlated with a heightened biofouling phenomenon. The total quantity of EPS in the mixed liquor can be divided into soluble microbial products (SMP) and EPS bound to the microbial flocs. In principle, these fractions need to be collected separately to be further analyzed (for more details on EPS extraction methods, see Domínguez et al. [61]). With the implementation of Rhodococcus sp. BH4 as a QQ bacterium, Maqbool et al. [27] determined the amount of SMP in the mixed liquor by analyzing the supernatant from an AS sample (reference $\mathrm{n}^{\circ} 6$ in Table 1). A 90\% reduction in the SMP amount was recorded after 80 days of operation, indicating that Rhodococcus sp. BH4-mediated QQ had a strong effect on the EPS production. In addition, Lee et al. [26] recorded 52\% and $85 \%$ reductions in the amounts of proteins and polysaccharides in the mixed liquor, respectively (reference $\mathrm{n}^{\circ} 14$ in Table 1). It is important to quantify this effect since it has been shown that, in some cases, the solutes and colloids in the supernatant play a more important role in biofouling than the biological pellets $[62,63]$. Nevertheless, it is still worth mentioning that slight reductions in the amounts 
of bound EPS were obtained with the application of QQ, with $-32 \%$ and $-5 \%$ in the loosely-bound EPS (LB-EPS) and the tightly-bound EPS, respectively [27]. Lee et al. [26] also recorded an average reduction of $17 \%$ in the amount of bound EPS in mixed liquor.

Concerning the amount of AHL in the mixed liquor, given that these signal molecules are usually produced at very low concentrations (in the range of picograms to nanograms per liter) and that they are present as a complex mixture with different compounds, an extraction procedure is necessary before the quantification $[64,65]$. Several quantification methods to measure the AHL concentration after their extraction have been reported to date and are summarized by Siddiqui et al. [5]. Maqbool et al. [27] extracted the AHLs from the supernatant of a broth sample then analyzed them using HPLC. A much smaller AHL concentration was observed in the QQ-MBR than in the control MBR (qualitative results). Hence, Maqbool et al. [27] came to the conclusion that the implementation of Rhodococcus sp. BH4 leads to a biofouling reduction via the destruction of AHLs in the mixed liquor, which is consistent with previous studies [24]. This result shows that monitoring the AHL concentration in the mixed liquor could help evaluate the progress of the QQ activity in MBRs. However, no information about the evolution of this concentration during the MBR operation is provided in the studies noted in Table 1 , probably because of the very low amounts, which would make the quantification laborious.

Recently, Lee et al. [26] showed that QQ could have an effect on the floc size of the AS. In a pilot-scale MBR of $80 \mathrm{~L}$, they recorded a 17\% reduction in the average floc size. However, in a three-stage MBR of a total working volume of $450 \mathrm{~L}$, composed of three tanks of $150 \mathrm{~L}$ (anoxic, aerobic and membrane tank), QQ did not lead to major differences in floc size in each tank. Thus, there is no clear trend yet about the influence of Rhodococcus sp. BH4-mediated QQ on the floc size of the mixed liquor.

Finally, additional research into the effect of QQ on other properties such as zeta potential, viscosity, or Sludge Volume Index (SVI) is required to provide complementary data to understand exactly how Rhodococcus sp. BH4 affects the mixed liquor characteristics.

The effect of Pseudomonas sp. 1A1 on the sludge characteristics in an MBR has only been assessed in terms of SMP. Cheong et al. [52] have reported a $60 \%$ reduction in the amount of polysaccharides, whereas the reduction in proteins was merely $6 \%$ (references $n^{\circ} 4$ and 5 in Table 2). These results suggest that Pseudomonas sp. 1A1-mediated QQ targets the QS-controlled genes in charge of the production of polysaccharides in a more pronounced way. However, at the current stage and with the few elements known so far, it is still hard to unravel the effect of Pseudomonas sp. 1A1-mediated QQ on the mixed liquor characteristics. Nevertheless, it is worth mentioning that some studies have investigated the QQ potential of a commercial purified acylase (porcine kidney I) that is believed to have the same mode of action as the acylase from Pseudomonas sp. 1A1. Yeon et al. [37] have reported reductions in the protein and the polysaccharide concentrations in the mixed liquor of approximately $60 \%$ and $20 \%$, respectively, and Jiang et al. [34] found a $20 \%$ reduction in both the protein and the polysaccharide concentrations. Thus, there is no clear trend revealing the kind of biofilm-related genes that are affected when acylase-mediated $Q Q$ is used.

Concerning the physical characteristics of the mixed liquor, the application of the purified acylase mentioned above resulted in a lower SVI, apparent viscosity and mean particle size, and a higher zeta potential, suggesting a better filterability [34]. More investigations should be carried out though, to confirm these observations and to investigate exactly how Pseudomonas sp. 1A1-mediated QQ affects the mixed liquor characteristics.

\subsection{Effect on the Biodegradation Efficiencies in the MBR}

The effect on the MBR performance should obviously be evaluated to make sure the implementation of Rhodococcus sp. BH4-mediated QQ does not impair the MBR treatment capacities. For nine of the studies considered in Table 1 (references $n^{\circ} 5$ to 13), this was assessed in terms of Chemical Oxygen Demand (COD) removal efficiencies and resulted in very negligible variations (less than a $3 \%$ modification compared to the control MBR) $[25,27,50,51]$. The fact that the COD removal efficiencies remained practically unchanged indicates that the use of Rhodococcus sp. BH4 as QQ bacteria induces no 
adverse effect on the ability of the biomass to metabolize the organic matter in the MBR. The same approach was used to assess Total Kjeldahl Nitrogen (TKN) removal and resulted in less than a 5\% variation compared to the control MBR, when the Rhodococcus sp. BH4 cells were entrapped in CEBs, microbial vessels or RMCF (data not shown) [51]. For Lee et al. [26], neither the total nitrogen removal efficiency nor the ammonia-nitrogen (NH4-N) removal efficiency was significantly affected when Rhodococcus sp. BH4-meadiated QQ was used in a pilot-scale MBR. Therefore, these findings confirm that Rhodococcus sp. BH4-mediated QQ effectively mitigates biofouling without affecting the MBR treatment performance.

The implementation of Pseudomonas sp. 1A1 to mitigate biofouling in an MBR resulted in COD removal efficiencies exceeding 95\%, which is not significantly different compared to that of the control MBR [38,52]. Thus, Pseudomonas sp. 1A1 is believed to induce no effect on the degradation of organics in MBRs. However, no information is available yet in the literature concerning the nitrogen removal efficiency.

\section{Effect of Bacterial QQ on the MBR Performance at Microscopic Scale}

At microscopic scale, the effect of bacterial QQ can be highlighted by the observation and the characterization of the biocake formed on the membrane.

\subsection{Effect on the Amount of Biofilm}

Biofouling is known to result from biocake formation on the membrane surface, of which biofilm (cells + EPS) is a major component. When studying biofouling in MBRs, the observation of biocake or biofilm becomes particularly relevant to determine whether the mitigation strategy employed, Rhodococcus sp. BH4-mediated QQ in this case, reduces biofilm formation effectively. In this context, membranes are usually taken out at the end of operation and specimens are cut off to measure the Total Attached Biomass (TAB) and/or to conduct microscopic observations using Confocal Laser Scanning Microscopy (CLSM) to evaluate the biofilm morphology. An approximate $50 \%(w / w)$ reduction in TAB has been reported after 1.7 and 9 days of operation by Oh et al. [28] and Kim et al. [50], respectively, while Kim et al. [25] recorded a 70\% reduction after only 3 days of operation, which was in accordance with the CLSM observations (references $n^{\circ} 1,5$ and 13 in Table 1). Lee et al. [26] recorded the most pronounced reduction in TAB with almost $90 \%$ after 14 days of operation (reference $n^{\circ} 14$ in Table 1 ). These findings clearly highlight the effectiveness of Rhodococcus sp. BH4-mediated QQ in reducing the amount of biofilm. However, complementary quantitative data on the biofilm thickness, porosity, etc., would be pertinent to identify possible structural modifications induced by Rhodococcus sp. BH4-mediated QQ.

Little is known about the effect of Pseudomonas sp. 1A1-mediated QQ at the microscopic scale since only two studies on that subject have been published to date [38,52]. However, Cheong et al. [52] obtained a $60 \%$ reduction in the TAB on the membrane when Pseudomonas sp. 1A1 bacteria-encapsulating CMV was used in the MBR (reference $n^{\circ} 2$ in Table 2).

\subsection{Effect on the Biofilm Composition}

The biofilm composition is usually discussed in terms of EPS amounts. First, the biocake is detached from the used membrane by placing it in a water tank equipped with an air-scouring system and/or with sonication followed by an air-scouring system [25]. Finally, EPS are extracted from the biocake in suspension using the Cation Exchange Resin (CER) method developed by Jahn and Nielsen [66].

When Rhodococcus sp. BH4 was introduced into lab-scale MBRs to assess its QQ potential, Kim et al. [25] reported an 80\% reduction in the total amount of EPS in the biocake after only 3 days of operation (reference $n^{\circ} 5$ in Table 1). Lee et al. [26] obtained a $20 \%$ reduction in the amount of proteins, whereas the amount of polysaccharides remained practically unchanged (reference ${ }^{\circ} 14$ in Table 1). On the other hand, the amounts of proteins and polysaccharides in the biocake were reduced 
by approximately $50 \%$ and $90 \%$ after 32 days of operation Kim et al. [50] (reference $\mathrm{n}^{\circ} 13$ in Table 1 ). These findings support the assumption that Rhodococcus sp. BH4-mediated QQ mitigates biofouling by decreasing the EPS production in the biofilm.

Concerning Pseudomonas sp. 1A1, the composition of biofilm, was reduced of about $80 \%$ and $40 \%$ in proteins and polysaccharides, respectively (reference $n^{\circ} 4$ in Table 2).

\section{Effect of the Operating Conditions on the Effectiveness of Bacterial QQ}

It is of great interest to investigate the effects of the operating conditions on the effectiveness of bacterial QQ, in order to identify the optimal conditions that offer the most substantial mitigation of biofouling.

\subsection{Effect of the Initial Quantity of $Q Q$ Bacteria Inserted into the $M B R$}

The quantity of Rhodococcus sp. BH4 initially inserted into the entrapping element in the MBR using PE microbial vessels has been studied for its potential effect on Rhodococcus sp. BH4-mediated QQ [40]. Oh et al. [40] reported that 13 days were required to reach the TMP of $30 \mathrm{kPa}$ in a lab-scale MBR containing two PE microbial vessels packed with $8.9 \mathrm{~g} \mathrm{BH} 4 / \mathrm{m}^{2}$ of the vessel surface area, whereas it took 28 days to reach the same TMP in a lab-scale MBR containing two vessels packed with $17.8 \mathrm{~g}$ $\mathrm{BH} 4 / \mathrm{m}^{2}$ of the vessel surface area (data not shown). A similar study has been reported using beads entrapping Rhodococcus sp. BH4 [51]. Two kinds of beads were prepared: with $1.5 \mathrm{mg} \mathrm{BH} 4 / \mathrm{cm}^{3}$ of bead volume (beads I) and with $7.5 \mathrm{mg} \mathrm{BH} 4 / \mathrm{cm}^{3}$ of bead volume (beads II). The two beads were placed in continuous lab-scale MBRs under the same operating conditions (references $n^{\circ} 7$ and 8 in Table 1). Beads I reduced the TMP by $93 \%$ (reference $n^{\circ} 8$ in Table 1 ), whereas beads II achieved almost $100 \%$ (reference $\mathrm{n}^{\circ} 8$ in Table 1 ). This result is thus consistent with the previous study with the microbial vessels, i.e., the greater quantity gave rise to a more significant delay of biofouling whatever the QQ device. However, the examination of a wider range of initial quantities of Rhodococcus sp. BH4 would be of great interest to determine an optimal quantity of cells to be introduced.

Cheong et al. [52] also experimented this effect by inserting two different initial quantities of Pseudomonas sp. 1A1 into the CMV: 26.5 and $70.3 \mathrm{mg}$ biomass $/ \mathrm{cm}^{3}$-lumen (corresponding to 266.4 and $706.8 \mathrm{mg}$ biomass/L reactor respectively), both under the inner flow feeding mode. However, the permeate flux was not maintained constant for both initial quantities, which makes the results difficult to compare. Therefore, it could be interesting to evaluate the effect of the initial quantity on the QQ effectiveness, all other operating conditions the same.

Finally, assessments of effect of the filtration mode (continuous, relaxation, backwash), the membrane design (material, geometry, configuration), the entrapping method, or the aeration rate, could be particularly relevant in an attempt to optimize application of Pseudomonas sp. 1A1-mediated QQ.

The operating conditions mentioned here are the only ones that have been investigated to date. However, other parameters such as the aeration rate, the total working volume, and the recirculation rate in a side-stream MBR, should be examined for their potential influence on the effectiveness of Pseudomonas sp. 1A1-mediated QQ.

\subsection{Effect of the Entrapping Method}

The mass transfer question has been further moved ahead by an analysis of the effect of the entrapping method on the Rhodococcus sp. BH4 efficiency in mitigating biofouling. The three entrapping methods mentioned above (microbial vessels, beads and RMCF) were compared under the same operating conditions with the same quantity of Rhodococcus sp. BH4 [51] (references $\mathrm{n}^{\circ} 10$ to 12 in Table 1). After 1 day of operation, beads were found to be the most efficient, with a reduction of $90 \%$ in the TMP level (reference $n^{\circ} 10$ in Table 1) and the microbial vessel was the least efficient to reduce biofouling (reference $\mathrm{n}^{\circ} 11$ Table 1 ).

It is noteworthy that the TMP jump obtained with the beads seems to be the most pronounced, with only a $14 \%$ fall in the TMP at the end of operation. This observation still remains unexplained, 
though Köse-Mutlu et al. [51] proposed a global assessment of the BH4 QQ effectiveness based on the ratio between the areas under the TMP curves. Consequently, based on these ratios, it was concluded that the more mobile the QQ device is, the more efficient is the biofouling mitigation via Rhodococcus sp. BH4-mediated QQ. This can be attributed to the higher frequency of contacts between QQ media and AHL molecules promoted by the movement of QQ media. Another reason would be that the free movement of the beads induces collisions between beads and membrane, resulting in physical cleaning in addition to the QQ effect, which thus enhances biofouling mitigation. This is consistent with previous studies demonstrating that vacant beads (with no Rhodococcus sp. BH4) or other inert particles also had the ability to reduce biofouling through a physical washing action that considerably delayed the time before the TMP jump was reached $[25,67]$.

\subsection{Effect of the Materials Used in the QQ Device}

The effect of the microbial vessel material on the QQ effectiveness has also been investigated [40]. Four kinds of microbial vessels were designed, with different materials, pore sizes, surface areas and inner volumes. Each of the four vessels was packed with the same quantity of QQ bacteria (30 mg $\mathrm{BH} 4$ /vessel). The influence of the microbial vessel design on the QQ effectiveness was evaluated for approximately 40 days of operation in MBRs with a working volume of $20 \mathrm{~L}$. At certain times, the vessels were removed from the MBR to measure their QQ activity based on the degradation rate of C8-HSL over 45 days. The modified polyethersulfone membrane (PESM), which had the largest inner volume $(0.98 \mathrm{~mL})$, was found to offer the highest QQ activity, with around $60 \%$ after 45 days. In comparison, the PE membrane and the two PVDF membranes with smaller inner volumes $(0.20$, 0.31 and $0.29 \mathrm{~mL}$, respectively) only resulted in $20 \%-45 \%$ after 45 days. This was attributed to the fact that the largest volume offered more space for the Rhodococcus sp. BH4 growth.

\subsection{Effect of the Location of the Microbial Vessel in the MBR}

The effect of the specific location of the microbial vessel inside the MBR is another important factor that has been investigated. Jahangir et al. [49] designed a side-stream MBR (or external submerged MBR) with a total working volume of $2.8 \mathrm{~L}$ consisting of a bioreactor tank (2 L) and a membrane tank $(0.8 \mathrm{~L})$, with continuous recirculation between the two tanks $(7.5$ to $30 \mathrm{~mL} / \mathrm{min})$. The operating conditions are noted in Table 1 (references $n^{\circ} 2$ and 3). In order to highlight the significance of the location of Rhodococcus sp. BH4 strain in the MBR, the microbial vessel was placed either in the bioreactor tank or in the membrane tank to carry out a comparative study in terms of TMP level. An overall enhancement of the Rhodococcus sp. BH4-mediated QQ activity was obtained when the microbial vessel was near the membrane, with a 50\% reduction in the TMP after 1 day of operation and about an $80 \%$ reduction at the end of the operation. The corresponding reductions were approximately $20 \%$ and $35 \%$ when the microbial vessel was in the bioreactor. The time required to reach a TMP of $25 \mathrm{kPa}$ was extended by $160 \%$ when the vessel was in the membrane tank, whereas, it was delayed by only $110 \%$ when the vessel was in the bioreactor. Therefore, the closer the microbial vessel is to the membrane, the greater is the capacity of Rhodococcus sp. BH4 to mitigate biofouling through QQ activity. This finding is of primary importance because it gives essential information about the AHLs that Rhodococcus sp. BH4-mediated QQ targets. In this case, it is assumed that the AHLs in the biofilm on the membrane surface play a more significant role in biofouling than the AHLs from the mixed liquor. In addition, the importance of the question of mass transfer is raised again with this experiment since the nearer the QQ enzyme (intracellular AHL-lactonase) was to its substrate (AHLs from biofilm), the more pronounced was the biofouling mitigation in the QQ MBR.

\subsection{Effect of the Recirculation Rate in a Side-Stream MBR}

With the same side-stream MBR as above (or external submerged MBR), Jahangir et al. [49] considered the Rhodococcus sp. BH4-mediated QQ effectiveness as a function of the recirculation rate between the two tanks. For that purpose, the recirculation rate was set to $7.5,15$ and $30 \mathrm{~mL} / \mathrm{min}$ and 
the effect on QQ effectiveness was assessed in terms of TMP. It was found that the QQ effectiveness increased with the recirculation rate, for both of the microbial vessel positions (data not shown). Besides, the QQ effectiveness appeared to be much more enhanced by an increased recirculation rate when the microbial vessel was in the membrane tank, than when it was in the bioreactor. These results again reinforce the significance of molecules transport, since they indicate that a greater recirculation rate promotes the transport of AHLs from the biofilm on the membrane surface so that they can be degraded inside the microbial vessel.

\subsection{Effect of Coupled Physical Cleaning Methods}

Another study focused on the coupling of Rhodococcus sp. BH4-mediated QQ with two physical cleaning modes: relaxation and air backpulse [30]. The former consisted in a short break (1 min) after 19 or 29 min of filtration, while the latter consisted in injecting compressed air into the lumen side of the membrane for $20 \mathrm{~s}$. In MBRs equipped with Rhodococcus sp. BH4-entrapping microbial vessels, TMP monitoring over approximately 20 days of operation revealed that the QQ+air backpulse combination gave rise to a more significant biofouling reduction than QQ+relaxation (data not shown).

\subsection{Effect of the Permeate Flux}

The effect of the permeate flux on the Rhodococcus sp. BH4-mediated QQ effectiveness was also investigated with beads as the entrapping method. Köse-Mutlu et al. [51] reported that an increase in the permeate flux from 30 to $50 \mathrm{~L} / \mathrm{m}^{2} \cdot \mathrm{h}$ severely impacted the Rhodococcus sp. BH4-mediated QQ effectiveness in terms of TMP reduction at the end of operation $\left(-97 \%\right.$ at $30 \mathrm{~L} / \mathrm{m}^{2} \cdot \mathrm{h}$ versus $-14 \%$ at $50 \mathrm{~L} / \mathrm{m}^{2} \cdot \mathrm{h}$ ). This can be explained by the fact that the formation of biocake is facilitated by the driving forces created with a high permeate flux. Another possible explanation is that the transport of AHLs from the biocake to the entrapped Rhodococcus sp. BH4 cells can be strongly counteracted by a high permeate flux.

In addition to the previous operating conditions, it could be of interest to investigate the effects of other parameters such as the aeration rate or the total working volume on the effectiveness of the Rhodococcus sp. BH4-mediated QQ with a view to identifying the optimal value for QQ efficiency.

From evaluations of the permeate flux using Pseudomonas sp. 1A1, it has been reported that a decrease in the permeate flux from $30 \mathrm{~L} / \mathrm{m}^{2} \cdot \mathrm{h}$ to $25 \mathrm{~L} / \mathrm{m}^{2} \cdot \mathrm{h}$ gives rise to slower biofouling (references $\mathrm{n}^{\circ} 2$ and 3 in Table 2). As presented in Table 2, the Pseudomonas sp. 1A1 effect on biofouling mitigation seems to be unchanged, since the TMP was reduced by approximately $80 \%$ at the end of the MBR operation with the addition of QQ, under both of the permeate fluxes. Thus, modification of the permeate flux seemed to have no specific effect on the QQ effectiveness, but did have an effect on the biofouling kinetics in both the control and the QQ MBRs.

\subsection{Effect of the Feeding Mode in Case of CMV for Entrapping Pseudomonas sp. 1A1}

When a CMV was used as an entrapping device, the feeding mode made a significant difference in the performance of the QQ MBR [52]. The CMV was composed of a central lumen surrounded by six other lumens in a circle, into each of which Pseudomonas sp. 1A1 was inserted (Figure 4c). The experiments carried out with $266.4 \mathrm{mg} / \mathrm{L}$ of Pseudomonas sp. 1A1 initially inserted into the MBR and with a permeate flux of $35 \mathrm{~L} / \mathrm{m}^{2} \cdot h$, showed that the inner flow feeding mode (i.e., MBR fed though the central lumen of the submerged CMV) resulted in an overall enhancement of the QQ effectiveness compared to the normal feeding mode (directly in the MBR tank) (references $\mathrm{n}^{\circ} 4$ and 5 in Table 2). The TMP rise-up corresponding to the inner flow feeding mode was substantially delayed compared with that corresponding to the normal feeding flow, the TMP being approximately $60 \%$ at the end of the operation for the inner mode, versus $25 \%$ lower for the normal mode. In addition, the effect on the mixed liquor and the biocake composition in terms of EPS was more pronounced when the inner flow feeding mode was used (references $\mathrm{n}^{\circ} 4$ and 5 in Table 2). Under the normal mode, Pseudomonas sp. 1A1 lost most of its QQ effectiveness over time with, with a $25 \%$ reduction in the TMP at the end of 
the operation, versus about $50 \%$ at the end of the first cycle (reference $n^{\circ} 5$ in Table 2), whereas the Pseudomonas sp. 1A1 activity remained practically unchanged under the inner mode (reference $\mathrm{n}^{\circ} 4$ in Table 2).

In conclusion, the inner flow feeding mode gave rise to enhanced QQ activity of Pseudomonas sp. 1A1. Cheong et al. [52] attributed these observations to the higher viability of the encapsulated cells that occurred with relatively fresher feed by the inner flow feeding mode. In fact, the inner feeding is believed to enhance the mass transfer of nutrients from the feed to the Pseudomonas sp. 1A1 encapsulated cells, promoting the growth of the bacteria as well as their acylase production. However, it can also be assumed that the inner flow feeding mode would foster the transport of acylases by driving them from the CMV lumens to the mixed liquor, thereby increasing their probability of encountering and degrading the signal molecules of AHL molecules. The latter hypothesis would need to be confirmed by a comparative study of acylase mass transfer through the CMV in the two feeding modes.

\section{Discussion and Concluding Remarks}

The results that have been presented in this review for the two QQ strains considered (Rhodococcus sp. BH4 and Pseudomonas sp. 1A1) highlight some interesting features of bacterial QQ for membrane biofouling mitigation in MBRs. The mode of action of each strain has been discussed through the nature and the localization of the QQ capacity and its effect on the MBR at both the macroscopic and the microscopic scales. The QQ effectiveness has been further discussed as a function of the operating conditions.

Both the strains considered showed a great potential to mitigate biofouling. However, even though the QQ bacteria considered are two particular cases that have been investigated so far, the confrontation of their assumed modes of action has helped underline some gaps in research on the application of QQ for membrane biofouling control in MBRs. Below, we attempt to summarize the main interrogations that remain unsolved to date.

- When studying the effect of the two bacteria on the progressive biofouling stage, it appeared that Pseudomonas sp. 1A1 had a less pronounced effect in terms of TMP reduction. Yet, it has been assumed that the effectiveness of Pseudomonas sp. 1A1 in mitigating membrane biofouling could be expected to be more significant, given that the QQ enzyme that it produces (acylase) is extracellular. Hence, a comparative study with Rhodococcus sp. BH4 under the exact same conditions could help identify the possible differences between these two QQ bacteria.

- In this work, the presentation of the $Q Q$ activity localization and the entrapping methods for both the QQ bacteria considered helped underline that the transport of the main molecules involved in the QQ process (AHLs as substrates and lactonases or acylases as QQ enzymes) is not completely understood yet, although some assumptions have been made in that direction. Hence, an in-depth characterization of the transport of these molecules in the MBR should be carried out, given the MBR hydrodynamics and the variety of methods existing for QQ bacteria entrapment.

- The analysis of the bacterial QQ effect on the progressive biofouling stage has given some interesting clues about the time needed for the QQ activity to become significant in the MBRs. It appears that the QQ activity takes place in the early phase of the MBR operation for both Rhodococcus sp. BH4 and Pseudomonas sp. 1A1. Thus, it could be of great interest for both of these $Q Q$ strains to investigate which, of $Q Q$ enzyme production or $Q Q$ enzyme transport, is the limiting step in the QQ process for biofouling mitigation in MBRs.

- In all the studies considered in this review, the TMP jump was successfully delayed with the application of bacterial QQ over the run times investigated. However, bacterial QQ does not completely prevent biofouling; it simply postpones its occurrence. One of the hypotheses to explain this observation could be that other kinds of QS-controlled biofouling become prevalent in the MBRs. Thus, the relationship between biofouling and other kinds of autoinducers present 
in the MBR (i.e., AIPs and AI-2s) should be investigated, and might lead to a more efficient QQ strategy to mitigate biofouling.

We discussed QQ for membrane biofouling mitigation in MBRs based on the detailed functioning of two particular QQ bacteria: Rhodococcus sp. BH4 and Pseudomonas sp. 1A1. The information gathered for that purpose led to the conclusion that bacterial $Q Q$ appears to be a promising strategy to fight the main obstacle that currently hinders the spread of MBRs: biofouling. The application of bacterial QQ to MBRs gave very good results that could be quantified at both the macroscopic and the microscopic scales. Besides, QQ was found to induce significant energy savings in MBRs. As an example, about $30 \%$ of reduction in the specific aeration energy demand was obtained in a lab-scale QQ-MBR [30], and the filtration energy consumption was reduced by approximately 50\% in a lab-scale QQ-MBR equipped with a chlorine-based backwashing system [68]. The bacterial QQ was also found to be effective to reduce biofouling in a pilot-scale MBR fed with real WW. Moreover, Lee et al. [26] recently demonstrated in a pilot-scale MBR that the application of QQ could reduce by approximately $60 \%$ the biofouling related energy consumption. Thus, the fact that the application of bacterial QQ leads to a significant reduction in both the energy consumption and the operating costs is an additional strong advantage showing that this is a viable method that could be used as the sole anti-biofouling strategy or, at least in the near future, as a complement to physical cleaning methods.

On the other hand, it appeared that the QQ effectiveness in mitigating biofouling depends on the MBR operating conditions. Consequently, it has been reported that, the greater the initial quantity of QQ bacteria (Pseudomonas sp. 1A1 or Rhodococcus sp. BH4) inserted in the MBR, the more efficient bacterial QQ can be to reduce membrane biofouling. Concerning the different entrapping methods, it has been demonstrated that the mobile entrapping elements (RMCF, CEBs and macrocapsules) give rise to enhanced QQ effectiveness in comparison to the stationary microbial vessel, probably because of the shear forces they create, which would promote the transport of the AHLs and/or induce a direct physical cleaning effect of the biocake on the membrane. With the use of the microbial vessel, it has been shown that $\mathrm{QQ}$ is more effective to reduce biofouling when the vessel is closer to the membrane, which indicates that AHLs from the biocake play an important role in the QQ process. Also, a higher recirculation rate in a side-stream MBR has been found to result in heightened QQ effectiveness. Finally, the permeate flux has been identified as having a negative influence on the effectiveness of both the QQ bacteria (Pseudomonas sp. 1A1 and Rhodococcus sp. BH4) for the mitigation of membrane biofouling in MBRs.

Therefore, we can conclude that great efforts have been made to optimize the bacterial QQ process, in particular by investigating the possible relationships between QQ effectiveness and the MBR operating conditions. Nevertheless, some crucial information is still missing and future research should focus on the few gaps revealed in order to make the application of bacterial QQ conceivable for membrane biofouling mitigation in MBRs in the near future.

Supplementary Materials: The supplementary materials are available online at http:/ www.mdpi.com/20770375/6/4/52/s1. Figure S1: AHL-mediated QS in Gram-negative bacteria (1) Synthesis of the LuxI protein resulting from luxI gene transcription; (2) Synthesis of the LuxR receptor resulting from luxR gene transcription; (3) Biosynthesis of AHL catalyzed by the LuxI protein; (4) Diffusion of AHL out of the cell and increase of the extracellular concentration; (5) Increase of the intracellular concentration of AHL; (6) Formation of the LuxR-AHL complex; (7) Activation of the transcription of the target genes (biofilm-related genes) and luxI gene transcription (positive autoregulatory loop).

Acknowledgments: The authors sincerely thank the "Ministère de l'Enseignement Supérieur et de la Recherche" for the financial support, and the "Ministère des Affaires Etrangères" for making this international collaboration possible throughout a STAR project grant. Finally, the authors thank Susan Becker for proofreading this article.

Author Contributions: Naila Bouayed wrote the paper. Nicolas Dietrich, Christine Lafforgue and Christelle Guigui supervised the work. Chung-Hak Lee took part to the discussions.

Conflicts of Interest: The authors declare no conflict of interest. 


\section{Nomenclature}

\begin{tabular}{|c|c|}
\hline AHL & $N$-acyl-L-homoserine lactone \\
\hline AI & Autoinducer \\
\hline AS & Activated Sludge \\
\hline CEB & Cell Entrapping Bead \\
\hline CLSM & Confocal Laser Scanning Microscope \\
\hline CMV & Ceramic Microbial Vessel \\
\hline COD & Chemical Oxygen Demand \\
\hline EPS & Extracellular Polymeric Substances (or Exopolysaccharides) \\
\hline $\mathrm{F} / \mathrm{M}$ & Food-to-Mass ratio \\
\hline $\mathrm{HF}$ & Hollow Fiber \\
\hline HPLC & High Performance Liquid Chromatography \\
\hline HRT & Hydraulic Retention Time \\
\hline HSL & Homoserine Lactone \\
\hline LB (biofilm) & Loosely Bound \\
\hline LB (medium) & Luria-Bertani \\
\hline MBR & Membrane Bioreactor \\
\hline MEC & Magnetic Enzyme Carrier \\
\hline MLSS & Mixed Liquor Suspended Solids \\
\hline PBE & Piper Betle Extract \\
\hline PE & Polyethylene \\
\hline PESM & Modified Poly Ether Sulfone \\
\hline PVDF & Polyvinylidene fluoride \\
\hline QQ & Quorum Quenching \\
\hline QS & Quorum Sensing \\
\hline QSI & Quorum Sensing Inhibitors \\
\hline SMP & Soluble Microbial Product \\
\hline SRT & Solid Retention Time \\
\hline SVI & Sludge Volume Index \\
\hline TAB & Total Attached Biomass \\
\hline $\mathrm{TB}$ & Tightly Bound \\
\hline TMP & Transmembrane Pressure \\
\hline TKN & Total Kjeldahl Nitrogen \\
\hline WW & Wastewater \\
\hline WWT & Wastewater Treatment \\
\hline
\end{tabular}

\section{References}

1. Branda, S.S.; Vik, S.; Friedman, L.; Kolter, R. Biofilms: The matrix revisited. Trends Microbiol. 2005, 13, $20-26$. [CrossRef] [PubMed]

2. Flemming, H.-C.; Schaule, G.; Griebe, T.; Schmitt, J.; Tamachkiarowa, A. Biofouling-The Achilles heel of membrane processes. Desalination 1997, 113, 215-225. [CrossRef]

3. Lade, H.; Pual, D.; Kweon, J.H. N-Acyl Homoserine Lactone-Mediated Quorum Sensing with Special Reference to Use of Quorum Quenching Bacteria in Membrane Biofouling Control. BioMed Res. Int. 2014, 2014. [CrossRef] [PubMed]

4. Lade, H.; Paul, D.; Kweon, J.H. Quorum Quenching Mediated Approaches for Control of Membrane Biofouling. Int. J. Biol. Sci. 2014, 10, 550-565. [CrossRef] [PubMed]

5. Siddiqui, M.F.; Rzechowicz, M.; Harvey, W.; Zularisam, A.W.; Anthony, G.F. Quorum sensing based membrane biofouling control for water treatment: A review. J. Water Process Eng. 2015, 7, 112-122. [CrossRef]

6. Fuqua, W.C.; Winans, S.C.; Greenberg, E.P. Quorum sensing in bacteria: The LuxR-LuxI family of cell density-responsive transcriptional regulators. J. Bacteriol. 1994, 176, 269-275. [CrossRef] [PubMed]

7. Lim, S.; Kim, S.; Yeon, K.-M.; Sang, B.-I.; Chun, J.; Lee, C.-H. Correlation between microbial community structure and biofouling in a laboratory scale membrane bioreactor with synthetic wastewater. Desalination 2012, 287, 209-215. [CrossRef]

8. Luxmy, N.; Nakajima, F.; Yamamoto, K. Analysis of Bacterial Community in Membrane-Separation Bioreactors Byfluorescent in Situ Hybridization (FISH) and Denaturing Gradient Gelelectrophoresis (DGGE) Techniques. Available online: http:/ /www.iwaponline.com/wst/04110/wst041100259.htm (accessed on 15 October 2015). 
9. Waheed, H.; Hashmi, I.; Khan, S.J.; Kim, S.R.; Arshad, M.; Nasir, H. Microbial population dynamics and profiling of quorum sensing agents in membrane bioreactor. Int. Biodeterior. Biodegrad. 2015, 113, 66-73. [CrossRef]

10. Miller, M.B.; Bassler, B.L. Quorum Sensing in Bacteria. Annu. Rev. Microbiol. 2001, 55, 165-199. [CrossRef] [PubMed]

11. Parsek, M.R.; Greenberg, E.P. Acyl-homoserine lactone quorum sensing in Gram-negative bacteria: A signaling mechanism involved in associations with higher organisms. Proc. Natl. Acad. Sci. USA 2000, 97, 8789-8793. [CrossRef] [PubMed]

12. Waters, C.M.; Bassler, B.L. Quorum sensing: Cell-to-cell communication in bacteria. Annu. Rev. Cell Dev. Biol. 2005, 21, 319-346. [CrossRef] [PubMed]

13. Whitehead, N.A.; Barnard, A.M.L.; Slater, H.; Simpson, N.J.L.; Salmond, G.P.C. Quorum-sensing in Gram-negative bacteria. FEMS Microbiol. Rev. 2001, 25, 365-404. [CrossRef] [PubMed]

14. Williams, P. Quorum sensing, communication and cross-kingdom signalling in the bacterial world. Microbiology 2007, 153, 3923-3938. [CrossRef] [PubMed]

15. Davies, D.G.; Parsek, M.R.; Pearson, J.P.; Iglewski, B.H.; Costerton, J.W.; Greenberg, E.P. The Involvement of Cell-to-Cell Signals in the Development of a Bacterial Biofilm. Science 1998, 280, 295-298. [CrossRef] [PubMed]

16. Hall-Stoodley, L.; Stoodley, P. Developmental regulation of microbial biofilms. Curr. Opin. Biotechnol. 2002, 13, 228-233. [CrossRef]

17. Hammer, B.K.; Bassler, B.L. Quorum sensing controls biofilm formation in Vibrio cholerae. Mol. Microbiol. 2003, 50, 101-104. [CrossRef] [PubMed]

18. Labbate, M.; Queck, S.Y.; Koh, K.S.; Rice, S.A.; Givskov, M.; Kjelleberg, S. Quorum Sensing-Controlled Biofilm Development in Serratia liquefaciens MG1. J. Bacteriol. 2004, 186, 692-698. [CrossRef] [PubMed]

19. Parsek, M.R.; Greenberg, E.P. Sociomicrobiology: The connections between quorum sensing and biofilms. Trends Microbiol. 2005, 13, 27-33. [CrossRef] [PubMed]

20. Rice, S.A.; Koh, K.S.; Queck, S.Y.; Labbate, M.; Lam, K.W.; Kjelleberg, S. Biofilm Formation and Sloughing in Serratia Marcescens Are Controlled by Quorum Sensing and Nutrient Cues. J. Bacteriol. 2005, 187, 3477-3485. [CrossRef] [PubMed]

21. Shrout, J.D.; Chopp, D.L.; Just, C.L.; Hentzer, M.; Givskov, M.; Parsek, M.R. The impact of quorum sensing and swarming motility on Pseudomonas aeruginosa biofilm formation is nutritionally conditional. Mol. Microbiol. 2006, 62, 1264-1277. [CrossRef] [PubMed]

22. Waters, C.M.; Lu, W.; Rabinowitz, J.D.; Bassler, B.L. Quorum Sensing Controls Biofilm Formation in Vibrio cholerae through Modulation of Cyclic Di-GMP Levels and Repression of vpsT. J. Bacteriol. 2008, 190, 2527-2536. [CrossRef] [PubMed]

23. Xia, S.; Zhou, L.; Zhang, Z.; Li, J. Influence and mechanism of N-(3-oxooxtanoyl)-L-homoserine lactone (C8-oxo-HSL) on biofilm behaviors at early stage. J. Environ. Sci. 2012, 24, 2035-2040. [CrossRef]

24. Yeon, K.-M.; Cheong, W.-S.; Oh, H.-S.; Lee, W.-N.; Hwang, B.-K.; Lee, C.-H.; Beyenal, H.; Lewandowski, Z. Quorum Sensing: A New Biofouling Control Paradigm in a Membrane Bioreactor for Advanced Wastewater Treatment. Environ. Sci. Technol. 2009, 43, 380-385. [CrossRef] [PubMed]

25. Kim, S.-R.; Oh, H.-S.; Jo, S.-J.; Yeon, K.-M.; Lee, C.-H.; Lim, D.-J.; Lee, C.-H.; Lee, J.-K. Biofouling Control with Bead-Entrapped Quorum Quenching Bacteria in Membrane Bioreactors: Physical and Biological Effects. Environ. Sci. Technol. 2013, 47, 836-842. [CrossRef] [PubMed]

26. Lee, S.; Park, S.-K.; Kwon, H.; Lee, S.H.; Lee, K.; Nahm, C.H.; Jo, S.J.; Oh, H.-S.; Park, P.-K.; Choo, K.-H.; et al. Crossing the Border between Laboratory and Field: Bacterial Quorum Quenching for Anti-Biofouling Strategy in an MBR. Environ. Sci. Technol. 2016, 50, 1788-1795. [CrossRef] [PubMed]

27. Maqbool, T.; Khan, S.J.; Waheed, H.; Lee, C.-H.; Hashmi, I.; Iqbal, H. Membrane biofouling retardation and improved sludge characteristics using quorum quenching bacteria in submerged membrane bioreactor. J. Membr. Sci. 2015, 483, 75-83. [CrossRef]

28. Oh, H.-S.; Yeon, K.-M.; Yang, C.-S.; Kim, S.-R.; Lee, C.-H.; Park, S.Y.; Han, J.Y.; Lee, J.-K. Control of Membrane Biofouling in MBR for Wastewater Treatment by Quorum Quenching Bacteria Encapsulated in Microporous Membrane. Environ. Sci. Technol. 2012, 46, 4877-4884. [CrossRef] [PubMed]

29. Siddiqui, M.F.; Sakinah, M.; Singh, L.; Zularisam, A.W. Targeting N-acyl-homoserine-lactones to mitigate membrane biofouling based on quorum sensing using a biofouling reducer. J. Biotechnol. 2012, 161, 190-197. [CrossRef] [PubMed] 
30. Weerasekara, N.A.; Choo, K.-H.; Lee, C.-H. Hybridization of physical cleaning and quorum quenching to minimize membrane biofouling and energy consumption in a membrane bioreactor. Water Res. 2014, 67, 1-10. [CrossRef] [PubMed]

31. Dong, Y.-H.; Wang, L.-H.; Zhang, L.-H. Quorum-Quenching Microbial Infections: Mechanisms and Implications. Philos. Trans. Biol. Sci. 2007, 362, 1201-1211. [CrossRef] [PubMed]

32. Rasmussen, T.B.; Givskov, M. Quorum sensing inhibitors: A bargain of effects. Microbiology 2006, 152, 895-904. [CrossRef] [PubMed]

33. Siddiqui, M.F.; Sakinah, M.; Ismail, A.F.; Matsuura, T.; Zularisam, A.W. The anti-biofouling effect of Piper betle extract against Pseudomonas aeruginosa and bacterial consortium. Desalination 2012, 288, 24-30. [CrossRef]

34. Jiang, W.; Xia, S.; Liang, J.; Zhang, Z.; Hermanowicz, S.W. Effect of quorum quenching on the reactor performance, biofouling and biomass characteristics in membrane bioreactors. Water Res. 2013, 47, 187-196. [CrossRef] [PubMed]

35. Kim, H.-W.; Oh, H.-S.; Kim, S.-R.; Lee, K.-B.; Yeon, K.-M.; Lee, C.-H.; Kim, S.; Lee, J.-K. Microbial population dynamics and proteomics in membrane bioreactors with enzymatic quorum quenching. Appl. Microbiol. Biotechnol. 2012, 97, 4665-4675. [CrossRef] [PubMed]

36. Kim, J.-H.; Choi, D.-C.; Yeon, K.-M.; Kim, S.-R.; Lee, C.-H. Enzyme-Immobilized Nanofiltration Membrane To Mitigate Biofouling Based on Quorum Quenching. Environ. Sci. Technol. 2011, 45, 1601-1607. [CrossRef] [PubMed]

37. Yeon, K.-M.; Lee, C.-H.; Kim, J. Magnetic Enzyme Carrier for Effective Biofouling Control in the Membrane Bioreactor Based on Enzymatic Quorum Quenching. Environ. Sci. Technol. 2009, 43, 7403-7409. [CrossRef] [PubMed]

38. Cheong, W.-S.; Lee, C.-H.; Moon, Y.-H.; Oh, H.-S.; Kim, S.-R.; Lee, S.H.; Lee, C.-H.; Lee, J.-K. Isolation and Identification of Indigenous Quorum Quenching Bacteria, Pseudomonas sp. 1A1, for Biofouling Control in MBR. Ind. Eng. Chem. Res. 2013, 52, 10554-10560. [CrossRef]

39. Czajkowski, R.; Jafra, S. Quenching of acyl-homoserine lactone-dependent quorum sensing by enzymatic disruption of signal molecules. Acta Biochim. Pol. 2009, 56, 1-16. [PubMed]

40. Oh, H.-S.; Kim, S.-R.; Cheong, W.-S.; Lee, C.-H.; Lee, J.-K. Biofouling inhibition in MBR by Rhodococcus sp. BH4 isolated from real MBR plant. Appl. Microbiol. Biotechnol. 2013, 97, 10223-10231. [CrossRef] [PubMed]

41. Park, S.-Y.; Hwang, B.-J.; Shin, M.-H.; Kim, J.-A.; Kim, H.-K.; Lee, J.-K. N-acylhomoserine lactonase producing Rhodococcus spp. with different AHL-degrading activities. FEMS Microbiol. Lett. 2006, 261, 102-108. [CrossRef] [PubMed]

42. Uroz, S.; Oger, P.M.; Chapelle, E.; Adeline, M.-T.; Faure, D.; Dessaux, Y. A Rhodococcus qsdA-Encoded Enzyme Defines a Novel Class of Large-Spectrum Quorum-Quenching Lactonases. Appl. Environ. Microbiol. 2008, 74, 1357-1366. [CrossRef] [PubMed]

43. Uroz, S.; Chhabra, S.R.; Camara, M.; Williams, P.; Oger, P.; Dessaux, Y. N-Acylhomoserine lactone quorum-sensing molecules are modified and degraded by Rhodococcus erythropolis W2 by both amidolytic and novel oxidoreductase activities. Microbiology 2005, 151, 3313-3322. [CrossRef] [PubMed]

44. Wang, L.-H.; Weng, L.-X.; Dong, Y.-H.; Zhang, L.-H. Specificity and Enzyme Kinetics of the Quorum-quenching N-Acyl Homoserine Lactone Lactonase (AHL-lactonase). J. Biol. Chem. 2004, 279, 13645-13651. [CrossRef] [PubMed]

45. Sakr, M.M.; Anwar Aboshanab, K.M.; Aboulwafa, M.M.; Hassouna, N.A. Characterization and Complete Sequence of Lactonase Enzyme from Bacillus weihenstephanensis Isolate P65 with Potential Activity against Acyl Homoserine Lactone Signal Molecules. BioMed Res. Int. 2013, 2013. [CrossRef] [PubMed]

46. Sio, C.F.; Otten, L.G.; Cool, R.H.; Diggle, S.P.; Braun, P.G.; Bos, R.; Daykin, M.; Cámara, M.; Williams, P.; Quax, W.J. Quorum Quenching by an N-Acyl-Homoserine Lactone Acylase from Pseudomonas aeruginosa PAO1. Infect. Immun. 2006, 74, 1673-1682. [CrossRef] [PubMed]

47. Romero, M.; Diggle, S.P.; Heeb, S.; Cámara, M.; Otero, A. Quorum quenching activity in Anabaena sp. PCC 7120: Identification of AiiC, a novel AHL-acylase. FEMS Microbiol. Lett. 2008, 280, 73-80. [CrossRef] [PubMed]

48. Xu, F.; Byun, T.; Dussen, H.-J.; Duke, K.R. Degradation of $N$-acylhomoserine lactones, the bacterial quorum-sensing molecules, by acylase. J. Biotechnol. 2003, 101, 89-96. [CrossRef]

49. Jahangir, D.; Oh, H.-S.; Kim, S.-R.; Park, P.-K.; Lee, C.-H.; Lee, J.-K. Specific location of encapsulated quorum quenching bacteria for biofouling control in an external submerged membrane bioreactor. J. Membr. Sci. 2012, 411-412, 130-136. [CrossRef] 
50. Kim, S.-R.; Lee, K.-B.; Kim, J.-E.; Won, Y.-J.; Yeon, K.-M.; Lee, C.-H.; Lim, D.-J. Macroencapsulation of quorum quenching bacteria by polymeric membrane layer and its application to MBR for biofouling control. J. Membr. Sci. 2015, 473, 109-117. [CrossRef]

51. Köse-Mutlu, B.; Ergön-Can, T.; Koyuncu, İ.; Lee, C.-H. Quorum quenching MBR operations for biofouling control under different operation conditions and using different immobilization media. Desalination Water Treat. 2016, 57, 17696-17706. [CrossRef]

52. Cheong, W.-S.; Kim, S.-R.; Oh, H.-S.; Lee, S.H.; Yeon, K.-M.; Lee, C.-H.; Lee, J.-K. Design of Quorum Quenching Microbial Vessel to Enhance Cell Viability for Biofouling Control in Membrane Bioreactor. J. Microbiol. Biotechnol. 2014, 24, 97-105. [CrossRef] [PubMed]

53. Meng, F.; Chae, S.-R.; Drews, A.; Kraume, M.; Shin, H.-S.; Yang, F. Recent advances in membrane bioreactors (MBRs): Membrane fouling and membrane material. Water Res. 2009, 43, 1489-1512. [CrossRef] [PubMed]

54. Pollice, A.; Brookes, A.; Jefferson, B.; Judd, S. Sub-critical flux fouling in membrane bioreactors-A review of recent literature. Desalination 2005, 174, 221-230. [CrossRef]

55. Zhang, J.; Chua, H.C.; Zhou, J.; Fane, A.G. Factors affecting the membrane performance in submerged membrane bioreactors. J. Membr. Sci. 2006, 284, 54-66. [CrossRef]

56. Cho, B.D.; Fane, A.G. Fouling transients in nominally sub-critical flux operation of a membrane bioreactor. J. Membr. Sci. 2002, 209, 391-403. [CrossRef]

57. Hwang, B.-K.; Lee, W.-N.; Yeon, K.-M.; Park, P.-K.; Lee, C.-H.; Chang, In-S.; Drews, A.; Kraume, M. Correlating TMP Increases with Microbial Characteristics in the Bio-Cake on the Membrane Surface in a Membrane Bioreactor. Environ. Sci. Technol. 2008, 42, 3963-3968. [CrossRef] [PubMed]

58. Li, C.; Cabassud, C.; Guigui, C. Effects of carbamazepine in peak injection on fouling propensity of activated sludge from a MBR treating municipal wastewater. J. Membr. Sci. 2015, 475, 122-130. [CrossRef]

59. Li, C.; Cabassud, C.; Reboul, B.; Guigui, C. Effects of pharmaceutical micropollutants on the membrane fouling of a submerged MBR treating municipal wastewater: Case of continuous pollution by carbamazepine. Water Res. 2015, 69, 183-194. [CrossRef] [PubMed]

60. Massé, A.; Spérandio, M.; Cabassud, C. Comparison of sludge characteristics and performance of a submerged membrane bioreactor and an activated sludge process at high solids retention time. Water Res. 2006, 40, 2405-2415. [CrossRef] [PubMed]

61. Domínguez, L.; Rodríguez, M.; Prats, D. Effect of different extraction methods on bound EPS from MBR sludges. Part I: Influence of extraction methods over three-dimensional EEM fluorescence spectroscopy fingerprint. Desalination 2010, 261, 19-26. [CrossRef]

62. Bouhabila, E.H.; Ben Aim, R.; Buisson, H. Fouling characterisation in membrane bioreactors. Sep. Purif. Technol. 2001, 22-23, 123-132. [CrossRef]

63. Teychene, B.; Guigui, C.; Cabassud, C.; Amy, G. Toward a better identification of foulant species in MBR processes. Desalination 2008, 231, 27-34. [CrossRef]

64. Brelles-Mariño, G.; Bedmar, E.J. Detection, purification and characterisation of quorum-sensing signal molecules in plant-associated bacteria. J. Biotechnol. 2001, 91, 197-209. [CrossRef]

65. Li, X.; Fekete, A.; Englmann, M.; Götz, C.; Rothballer, M.; Frommberger, M.; Buddrus, K.; Fekete, J.; Cai, C.; Schröder, P.; et al. Development and application of a method for the analysis of $N$-acylhomoserine lactones by solid-phase extraction and ultra high pressure liquid chromatography. J. Chromatogr. A 2006, 1134, 186-193. [CrossRef] [PubMed]

66. Jahn, A.; Nielsen, P.H. Extraction of extracellular polymeric substances (EPS) from biofilms using a cation exchange resin. Water Sci. Technol. 1995, 32, 157-164. [CrossRef]

67. Teychene, B.; Guigui, C.; Cabassud, C. Engineering of an MBR supernatant fouling layer by fine particles addition: A possible way to control cake compressibility. Water Res. 2011, 45, 2060-2072. [CrossRef] [PubMed]

68. Weerasekara, N.A.; Choo, K.-H.; Lee, C.-H. Biofouling control: Bacterial quorum quenching versus chlorination in membrane bioreactors. Water Res. 2016, 103, 293-301. [CrossRef] [PubMed]

(C) 2016 by the authors; licensee MDPI, Basel, Switzerland. This article is an open access article distributed under the terms and conditions of the Creative Commons Attribution (CC-BY) license (http://creativecommons.org/licenses/by/4.0/). 